\title{
INTERFACIAL FLOW PATTERNS ON A STATIC LIQUID DROP WITH FORCED INTERNAL CIRCULATION
}

\author{
Fakhri F. Poonawalla
}

M.S. Thesis Submitted to Iowa State University

Ames Laboratory, ERDA

This report was prepared as an account of work sponsored by the United States Government. Neither the United States nor the United States Energy Research and Development Administration, nor any of their employees, nor any of their contractors, warranty, liability or express or implied, or assumes any legal or usefulness of any information, appact completeness process disclosed, or represents, that its use woduct or

Iowa State University

Ames, Iowa 50011

Date Transmitted: February 1977

PREPARED FOR THE U.S. ENERGY RESEARCH AND DEVELOPMENT ADMINISTRATION UNDER CONTRACT NO. W-7405-eng-82

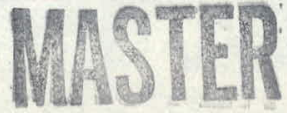




\section{DISCLAIMER}

This report was prepared as an account of work sponsored by an agency of the United States Government. Neither the United States Government nor any agency Thereof, nor any of their employees, makes any warranty, express or implied, or assumes any legal liability or responsibility for the accuracy, completeness, or usefulness of any information, apparatus, product, or process disclosed, or represents that its use would not infringe privately owned rights. Reference herein to any specific commercial product, process, or service by trade name, trademark, manufacturer, or otherwise does not necessarily constitute or imply its endorsement, recommendation, or favoring by the United States Government or any agency thereof. The views and opinions of authors expressed herein do not necessarily state or reflect those of the United States Government or any agency thereof. 


\section{DISCLAIMER}

Portions of this document may be illegible in electronic image products. Images are produced from the best available original document. 
This report was prepared as an account of work sponsored by the United States Government. Neither the United States nor the United States Energy Research and Development Administration, nor any of their employees, nor any of their contractors, subcontractors, or their employees, makes any warranty, express or implied, or assumes any legal liability or responsibility for the accuracy, completeness, or usefulness of any information, apparatus, product or process disclosed, or represents that its use would not inf ringe privately owned rights.

Available from: National Terhnical Information Service U. S. Department of Commerce P.O. Box 1553 Springfield, VA 22161

Price: Microfiche $\$ 3.00$ 


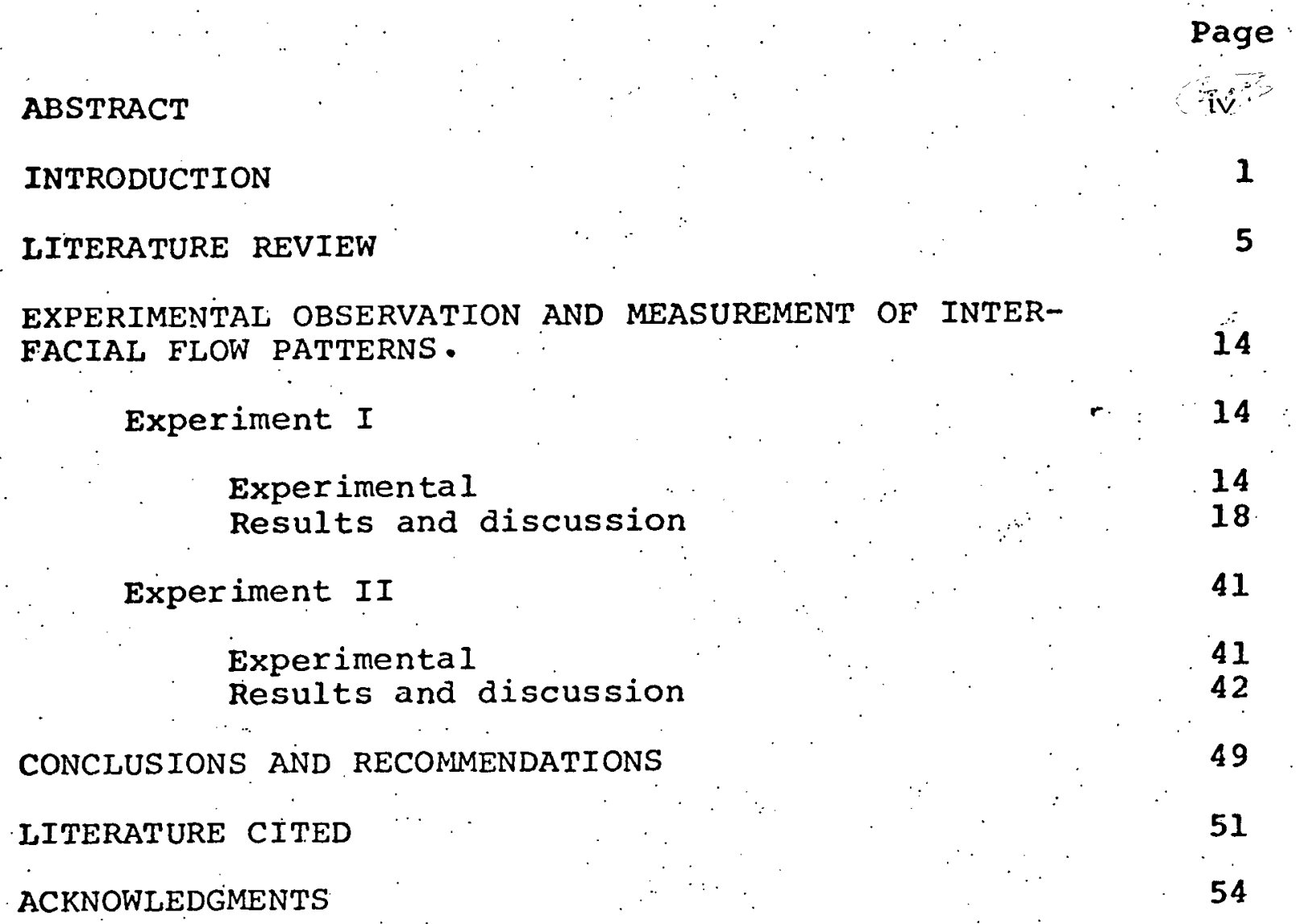




\section{ABSTRACT}

In the absence of interfacial turbulence and mass transfer, the interfacial motion on a forming liquid arop. results purely from shear transmitted by internal motion of the fluid inside the drop, just underneath the interface. The shear-induced motion in the interface was observed by placing light reflecting hollow glass beads on the interface of a static liquid drop with forced internal circulation and photographing their motion:

Two, four, and six symmetrical flow patterns were observed on the interface when the Reynolds number based on the density and viscosity of the drop fluid, the velocity through nozzle, and the nozzle diameter was varied over a range of $8-34,60-150$, and 220-270 respectively. The shape of each of the two pattern flows was approximately elliptical, while that of the four and six pattern flow was approximately triangular. The gradual change from two to four, and four to six patterns occurred in the range of Reynolds number $34-60$, and $150-220$ respectively. No: distinguishable motion was observed at Reynolds numbers less than 8 . 


\section{INTRODUCTION}

Many mass transfer operations in chemical engineering involve work with two phase systems where one phase is dispersed as droplets into a second continuous phase. The nature of this dispersion between the two phases has an important bearing on the efficiency of the equipment in which the operation is being carried out. The interfacial area between the two fluids determines the surface available for mass transfer and the motion of the fluid in each phase affects the transport of solute to and from the interface.

The study of mass transfer in drops has traditionally been divided into three areas representing an arbitrary division of the life of a drop into three stages - formation, steady rise or fall, and coalescence. Of these three stages, by far the greatest amount of work has been done on drops during the steady $x$ ise or fall period: Considerably less has. been done on forming or coalescing drops since both theoretical and experimental studies are more difficult to carry out:

As progress has been made in understanding the mechanisms of mass transfer in dispersed systems emphasis has shifted from a semi-empirical approach based on attempts to correlate measured results in terms of overall mass transfer coefficients to studies relating the hydrodynamics of drop systems to solute transport processes. Much work remains to 
be done but the results to date show clearly that this more fundamental approach provides significantly greater insight into the mechanisms of interphase mass transfer. The hydrodynamics of drops during steady rise or fall has been studied in detail with regard to shape, size distribution, velocity, and internal fluid motion within the drop phase. In particular, the motion inside the drop has been studied extensively because of its pronounced effect on mass transfer rates. As the drop travels through the continuous phase, shear forces may be transmitted across the interface and cause the fluid within to rotate in such a fashion that a toroidal flow pattern exists. This type of motion is called internal circulation. Mass transfer rates for drops with internal circulation are much higher than those in which such flow does not occur. The rotation of the fluid creates a flow path along which solute within the drop can reach the interface by bulk transport, a process that is much more rapid than transport by molecular diffusion in noncirculating drops.

Internal circulation in rising or falling drops can be studied by suspending a drop in a tapered glass tube. The flow of continuous phase past the drop is adjusted so that the position of the drop remains stationary. The mathematical solution for such a system is known for very low Reynolds number $\left(\mathrm{N}_{\mathrm{Re}}<1\right)$ and the theory agrees well with experimental 
results obtained by photographing droplets containing aluminum particles to permit visualization of the internal flow patterns.

Not much quantitative work has been done on the hydrodynamics of and internal circulation within forming drops. Until 1963, the evidence of internal circulation was largely indirect and circumstantial because of difficulty of maintaining internal circulation within a forming drop for a long enough period of time to make fruitful observations and measurements. In 1963, Constan and Calvert developed a technique of forced internal circulation which enabled the internal circulation to be maintained for longer times. since then, a number of investigators have experimentally studied internal circulation patterns within forming drops. Burkhart, Weathers and Sharer (1976) developed quantitative correlations for predicting the degree of internal circulation in forming drops and its effects on mass transfer rates over a Reynolds number range of 1 to 45 . Comparison of their results with those obtained by Rajan and Heideger (1971) who studied mass transfer from a forming drop to the surrounding medium in the absence of resistance to mass transfer in the drop phase strongly supports the interpretation of the latter authors that internal circulation in their drops created a shear force which was transmitted across the interface of the drop and contributed to a decrease in the mass transfer resistance 
in the continuous phase.

It is logical to anticipate that this transmission of shear across the drop interface may lead to motion in the plane of interface. The principal objective of this investigation was to study this shear-induced motion in the interface of a forming drop by creating a forced internal circulation pattern within the drop. The investigation was done in the absence of mass transfer and surface active agents. Lastly, it is necessary to differentiate the above shear-induced interfacial motion from motion in the interface which occurs due to unequal values of interfacial tension at random locations on the surface during mass transfer as a result of local changes in solute concentration in the interface. This surface driven motion is known as "interfacial turbulence" and the phenomenon which causes it is known as the Marangoni effect. 


\section{LITERATURE REVIEW}

There is a considerable body of quantitative evidence of internal circulation in rising or falling drops. Direct observations by motion picture and still photography have been used to establish the quantitative conditions for its existence. Comprehensive reviews of the literature in this field up to 1970 are given by Tavlarides et al. (1970), Gal-or et al. (1969), Soo (1967), Brodkey (1967) and Resnick and Gal-or (1968).

Literature on internal circulation dates back to 1911 when Hadamard (1911, 1912 as cited in Brodkey, R. S:, 1967 and Kintner, R. C., 1963) developed stream functions for the flow of fluid past a stationary liquid sphere. He showed that for a Reynolds number (based on drop diameter and physical properties of drop liquid) less than one, internal circulation within the drop did not occur and that such drops behaved essentially as solid spheres. The same stream functions were developed independently by Rybczynski (1911 as cited in Kintner, R. C., 1963 and Brodkey, R. S., 1967). In their mathematical analysis both authors assumed that all the forces in the interface were in equilibrium. One of these forces, the interfacial tension is a characteristic feature of the interface. Since the interface was assumed to be in equilibrium, the existence of interfacial tension forces did not contribute to the tangential stresses in the interface in their analysis, or, in other words, 
interfacial tension gradients were assumed to be zero.

Since then, most investigators were able to observe visually that internal circulation existed in rising or falling drops, and the observed patterns were very much like those predicted by Hadamard and Rybczynski even though the corresponding Reynolds numbers were too large for the theoretical model to be strictly satisfied.

Horton et al. (1965) measured velocity profiles inside drops suspended in a fluid flowing upward in a tapered glass tube. The Reynolds number based on the drop diameter and its physical properties was varied between 3.76 and 19. Even for Reynolds number as high as 19 their results compared favorably with Hadamard's theoretical relations, which are valid up to a Reynolds number of one. Rose and Kintner (1966) qualitatively observed internal velocity profiles within drops for Reymolds numbers well above 200. Even for such high Reynolds numbers their reported patterns were similar to those calculated by Hadamira.

Schechter and Farley (1963) incorporated the effects of interfacial tension gradients in a more detailed analysis of the problem of Hadamard: They obtained stream functions which included terms accounting for the effects of interfacial tension gradients and, by equating the stream function within the drop to zero obtained specific conditions of interfacial tension which would produce zero internal circulation 
within the drop. They also showed that internal circulation vanished if the viscosity of the drop fluid became infinite. Very recently, LeVan and Newman (1975) derived the stream functions for a spherical drop in creeping flow with an arbitrary surface tension gradient at its interface.

Although the fluid dynamics of freely rising or falling arops are reasonably well known, similar problems involving the hydrodynamics of drop formation have received very little attention. This is due in part to the fact that it is very difficult to isolate and maintain internal circulation for an extended period in a forming drop. The high speed photographic technique used for studying rising or falling drops can also be used for studying forming drops, but additional problems arise from the transient or unsteady state character of the formation period. This difficulty was not solved until 1963, when Constan and Calvert developed a technique for studying forced internal circulation which consisted of suspending a drop from two concentric nozzles in an atmosphere of the gas to be absorbed. Internal circulation was initiated by injecting liquid into the inner nozzle while simultaneously withdrawing an equal amount of liquid from the annulus. The internal circulation so generated could be maintained as long as it was possible to supply liquid to the inner nozzle. They used this technique to study the effects of internal circulation on the rate of absorption of $\mathrm{SO}_{2}$ by ; 
water.

In an attempt to simulate internal flow patterns within a forced circulation drop, Panno and Calvert (1963) visually observed the internal flow pattern in a large scale model consisting of a nozzle inserted into a large test tube which provided a hemispherical flow region. They divided the internal flow pattern into two zones, In zone $I$, fluid rose from the inlet nozzle to the apex of the drop where it changed direction. The action of the fluid in zone I was considered to be much the same as that of a submerged jet, where the flowing fluid undergoes both lateral diffusion and deceleration due to turbulence generated at the verges of the jet and simultaneously incorporates and accelerates liquid from the surrounding region into the main jet rising from the nozzle. Albertson (1950) in a study on diffusion of submerged jets established the relation for the velocity of this kind of jet as a function of height above the nozzle.

In zone II, the fluid moves from the point where it changes direction at the apex to a peripheral flow under the surface of the drop. This type of motion was considered to be the samie as that resulting from the impingement of a submerged jet on a flat plate and it has been investigated by Poreh and Cermak (1959). Using the results of these two authors it can be established that in zone II, the characteristics of the flow can be defined in terms of the velocity 
of the fluid issuing from zone $I$. Work is thus available to estimate fluid velocities in the plane of the incoming jet and in the general area of motion under the interface, although it should not yet be considered that these estimates are satisfactory.

Rajan and Heideger (1971) studied the mass transfer occurring between a liquid drop during its formation and the surrounding liquid phase. Slightly soluble organic drops containing no additional solute were formed in a continuous aqueous phase so that the only resistance to mass transfer was the continuous phase. Transfer occurred by diffusive and convective transport of the drop phase into the continuous phase from the interface of the drop.

They studied the effect of nozzle diameter and both phase flow rates on mass transfer coefficients. In all çases, the coefficients were initialiy very large but fell rapidly and then remained constant at a lower level. This : behavior implied that circulation generated in the drop by the velocity of the fluid leaving the nozzle exerted a significant influence on mass transfer. Since there was no. resistance to mass transfer on the drop side of the interface, the effect of internal circulation in the forming drop had to have been due to the transmission of shear-induced motion across the interface and into the adjacent water phase where the only mass transfer resistance was located. They 
also felt that the effect of internal circulation was strongest initially when drop size was small but did not report any observations or measurements of circulation in their drops.

Weathers (1970) studied internal circulation during drop formation by using high speed photography. He developed quantitative correlations for predicting the degree of internal circulation. His pictures of a static drop with forced internal circulation also revealed a thin region between the interface and the bulk of the drop, where the nature of the motion of the fluid could not be determined. Knowledge of the flow characteristics in this region would fill the gap existing between flows in the plane of the interface and internal circulation within the drop.

Sharer (1972) studied the transfer of acetic acid from a cyclohexane drop with forced internal circulation. He obtained three separate mass transfer regions for a drop as the Reynolds number based on the internal nozzle was varied. from 1 to 45 . These regions corresponded to the changes in flow patterns within the drop: low mass transfer at low rates, relatively high mass transfer at high flow rates, and a transition region.

A quantitative relationship existed between the internal flow patterns reported by Weathers (1970) and the three regions of mass transfer found by sharer (1972). The total mass 
transfer from the drop was very small when very little circulation was occurring in the interior of the drop. The maximum mass transfer occurred when there was complete circulation. The results of Sharer (1972) and Weathers (1970) when compared with the work of Rajan and.Heideger (1971) support the interpretation of the latter authors that internal circulation in their drops created a shear force which was transmitted across the interface of the drop and contributed to a decrease in the mass transfer resistance in the continuous phase.

Sandry (1973) obtained flow patterns within a constant volume forced internal circulation drop for various flow rates and viscosities by numerical solution of the NavierStokes equations. Increasing the viscosity while holding flow rate constant and vice versa caused a transition from rotating to nonrotating flow. For the first time he established theoretically that the occurrence of rotation was observed in a forming drop only above a Reynolds number of 0.8. The condition of $\mathrm{N}_{\mathrm{Re}}>0.8$ for internal circulation to occur in a forming drop is strikingly close to Hadamard's (1911) condition of $\mathrm{N}_{\mathrm{Re}}$ ? 1 for internal circulation to occur in a rising or falling drop.

A new technique of nondisturbing flow visualization has been developed by Popovich and Hummel (1967) and it could prove to be of considerable value in the study of the fluid, 
dynamics of drop formation from single nozzles. The technique involves the use of minute quantities of the chemical compound 1,3,3 trimethylindolino - 6' - nitrobenzopyrospiran as an indicator in the dispersed phase. This indicator produces extremely fine tracer time lines when irradiated with ultraviolet light from a pulsed nitrogen laser. Later, Humphrey and Hummel ${ }^{\circ}(1974)$ showed that high speed cinephotographs of the time lines could be used to estimate axial and radial velocity components of the fluid within the drop. They estimated axial and radial velocity components in forming drops of chlorobenzene, carbon tetrachloride and tributyrin by means of a numerical mass balance technique.

- By substituting thesevelocity components in the NavierStokes equations, they also showed how axial and radial pressure distributions could be obtained within a forming drop. They lacked enough experimental points to accurately find the first and second derivatives of the velocity components for substitution in Navier-Stokes equations and thus their pressure distribution was qualitative in nature and subject to large error, the paper still represents a significant contribution.

The same authors have also developed a model which can be used to correct optical distortions due to differences in the refractive indices of the two phases. This model has 
been developed for a growing drop and is different from that proposed by Kintner et al. (1961) for freely suspended drops. No work has been reported in the literature on the interfacial flow patterns observed and reported in the dissertation resulting from shear forces induced in the interface by bulk flow within the drop. The work described here, then, represents the first reported data on the subject. 


\section{EXPERIMENTAL OBSERVATION AND MEASUREMENT \\ OF INTERFACIAI FLOW PATTERNS}

Two types of experiments were performed to observe and record interfacial flow patterns. In Experiment I, the interfacial flow patterns on the curved interface of a drop were studied. The interfacial flow patterns were produced by the forced internal circulation of fluid within the drop. In Experiment II, the interfacial flow patterns on a flat horizontal air-water interface were studied. The motion on the interface was produced by impingement of submergod water jet on the air-water interface.

\section{Experiment I}

\section{Experimental}

- A constant volume drop with forced internal cleculation was formed on a teflon nozzle having a central orlis through which dispersed plase was injected into tho drop and a concentric annular ring near the edge of the noszde trowh which fluid from the drop was withdrawn. The racos of jection and withdrawal were kept equal by means ot to ml. syringes operated simultaneously by a worm gaas ts the (Figure 1): The flow rate into the drop was conerolig 1/50 H.P., 7 in.-ib. torque Bodine variable spond thes a Minarik speed control. Two nozzles having conts of 


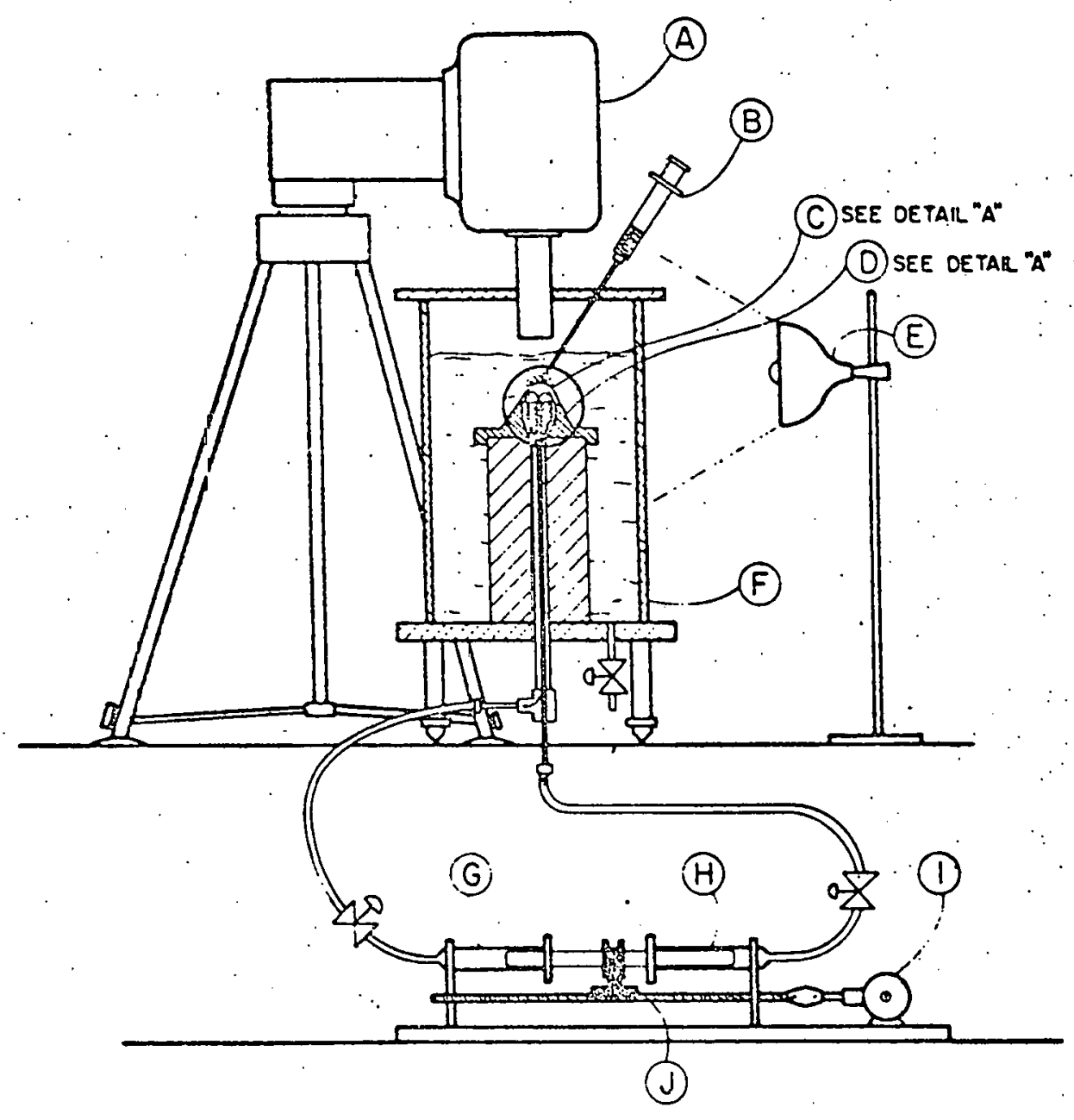

A DBM 5C HIGH SPEED MILLIKEN CAMERA

B $5 \mathrm{ml}$ SYRINGE (THROUGH WHICH HOLLOW GLASS SFHERES ARE PUT ON THE INTERFACE)

C LIQUID BUBBLE

D. TEFLON NOZZLE

E PHOTO FLOOD LAMP

F OUTER GLASS CHAMBER (FRLEO WITH OISTILLED WATERI

G SYRINGE (LIOUIO IS WITHORAWN FROM THE BUBBLE THROUGH THE ANNULAR RING)

H SYRINGE ILIQUID IS PUSHED INTO THE BUBBLE THROUGH THE INLET NOZZLE)

1 BODINE VARIABLE SPEED MOTOR

$\checkmark$ WORM GEAR DRIVE

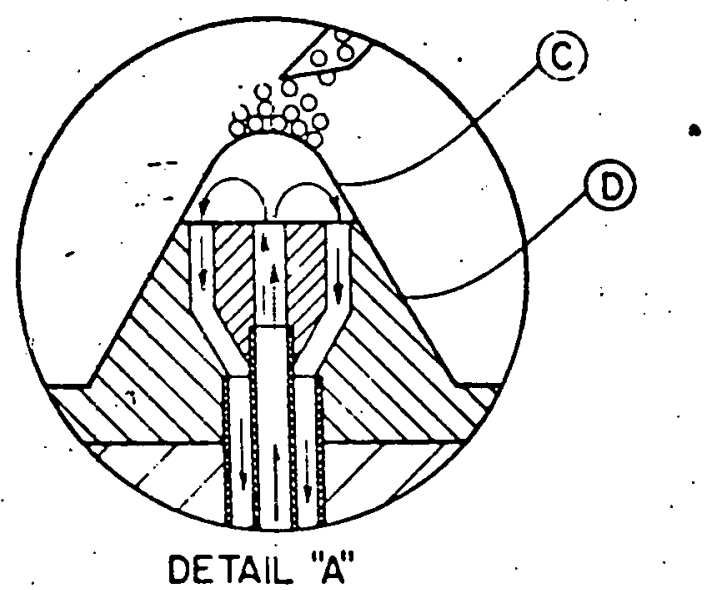

Figure 1. Schematic diagram of equipment used to study surface motion on a constant volume drop with forced internal circulation 
diameters of $0.132 \mathrm{~cm}$. and $0.264 \mathrm{~cm}$. were'used. The inner and outer diameter of the annulus for withdrawal of fluid from the drop was $0.953 \mathrm{~cm}$. and $1.092 \mathrm{~cm}$. respectively and the outside diameter of the nozzle was $1.374 \mathrm{~cm}$. The nozzle was surrounded by a $10 \mathrm{~cm} . \times 10 \mathrm{~cm}$. $\times 20 \mathrm{~cm}$. glass column carrying continuous phase, as shown in Figure 1 .

The dispersed phase was varsol, a light hydrocarbon mixture, and mineral oil mixed in varying proportions. The continuous phase was distilled water. Six mixtures of mineral oil and varsol were used in the volumetric ratios 10:1, $4: 1,2: 1,1: 1,1: 2$, and $0: 1$ to give a range of viscosities from $41.03 \mathrm{cp}$. to $0.96 \mathrm{cp}$. Table 1 gives values of viscosity, density, and interfacial tension of each of the above mixtures.

The volumetric flow rate of the dispersed organic phase was determined by calibrating the syringe drive system for each speed control setting used. Flow rates were such that the velocity of the dispersed phase through the central orifice varied from $2.63 \mathrm{~cm} . / \mathrm{sec}$. to $10.94 \mathrm{~cm} . / \mathrm{sec}$. for the $0.264 \mathrm{~cm}$. diameter orifice, and from $10.46 \mathrm{~cm} . / \mathrm{sec}$. to $27.40 \mathrm{~cm} . / \mathrm{sec}$. for the $0.132 \mathrm{~cm}$. diameter orifice. Higher velocities were not possible because of the occurrence of jetting which caused the surface of the drop to become unstable.

Light reflecting tiny hollow glass spheres $^{1}$ were placed

"Ecospheres" manufactured by Emerson and Cuming, Inc. 
Table 1. Physical properties of mineral oil-varsol mixture (Sharer 1972)

\begin{tabular}{cccc}
$\begin{array}{c}\text { Fluid } \\
\text { (by vil:varsol } \\
\text { (bolume) }\end{array}$ & $\begin{array}{c}\text { Viscosity } \\
\text { cp. }\end{array}$ & $\begin{array}{c}\text { Density } \\
\text { gm/cc }\end{array}$ & $\begin{array}{c}\text { Interfacial } \\
\text { Tension } \\
\text { dyne/cm. }\end{array}$ \\
\hline $10: 1$ & 41.03 & 0.858 & 43.3 \\
$4: 1$ & 19.46 & 0.849 & 36.6 \\
$2: 1$ & .9 .19 & 0.838 & 38.5 \\
$1: 1$ & 4.44 & 0.824 & 39.9 \\
$1: 2$ & 2.37 & 0.810 & 39.3 \\
Varsol & 0.96 & 0.780 & 35.8 \\
Temperature & 23.8 & 23.0 & 23.0 \\
\hline
\end{tabular}
meter.

aviscosity measured with Hoeppler falling ball visco-

${ }^{b}$ Density measured by Westphal balance.

CInterfacial tension measured by du Nuoy tensiometer.

on the interface of the drop from a $5 \mathrm{ml}$. syringe containing a water slurry of the particles. The motion of these particles was observed visually and photographed on $16 \mathrm{~mm}$. Eastman Double-X negative film at a rate of 64 frames/sec. using a Milliken DBM-5C camera placed vertically above the drop.

The developed films were then projected onto a screen by means of an L-W Motion Analyzer with which the film could be analyzed frame by frame or could be shown at a rate 
of 16 frames/sec., or 24 frames/sec. To obtain plots of particle trajectories, the films were analyzed frame by frame and the motion of a particle on the interface of the drop was traced on a sheet of white paper. The same film was rerun and the motion of an another particle was traced on the same sheet. The entire process was repeated with a large number of particles, until the nature of the flow could be distinctly observed on the paper.

\section{Results and discussion}

Definite flow patterns were observed on the interface of the drop. These patterns changed in number and shape with the viscosity of the drop phase, the velocity of the liquid through the orifice, and the orifice diameter. $A$ Reynolds number based on the inlet nozzle conditions was calculated for each run, and the changes in the flow patterns were found to be a distinct function of the Reynolds number.

Three types of flow patterns were observed on the interface. Depending on the condition of the run, there were two, four or six symmetrical patterns. Figure 2 a shows a top view and a front view of the particle paths on the interface of the drop as observed over a range of Reynolds numbers from 8 to 34 . The two pattern flows were elliptical in shape. Four and six patterns flows, as observed over a range of Reynolds numbers from $60-150$ and 220-270 respectively were 
Figure 2a. Two pattern flows observed on the arop interface over a range of Reynolds number $8-34$
Figure 2b. Four pattern flows observed on the drop interface over a range of Reynolds number 60-150
Figure 2c. Six pattern flows observed on the drop

interface over a range of Reynolds number 220270 

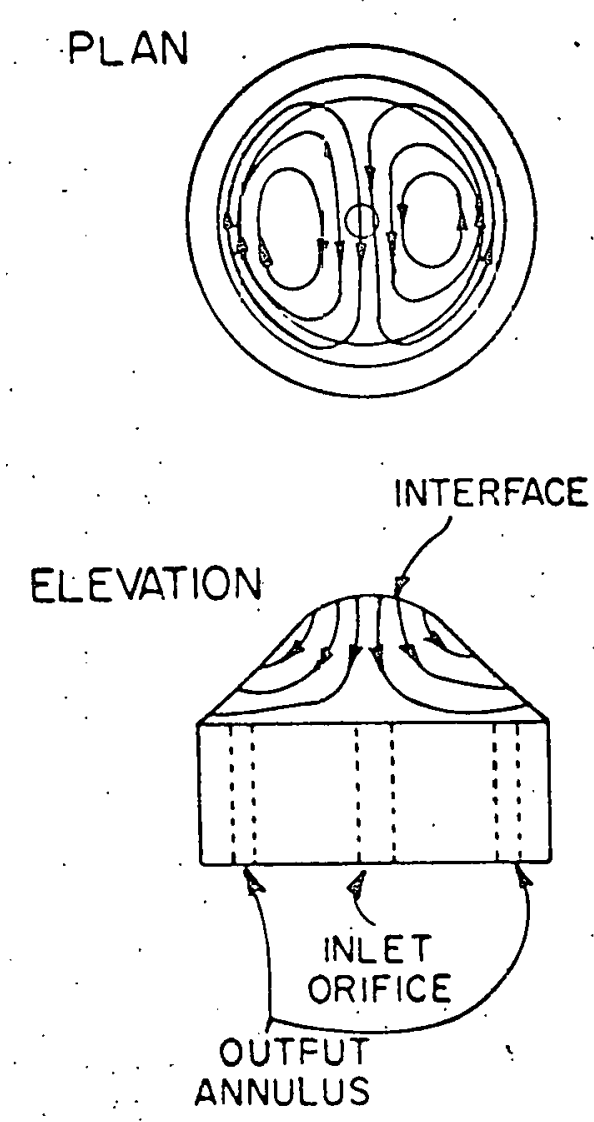

Figure $2 a$
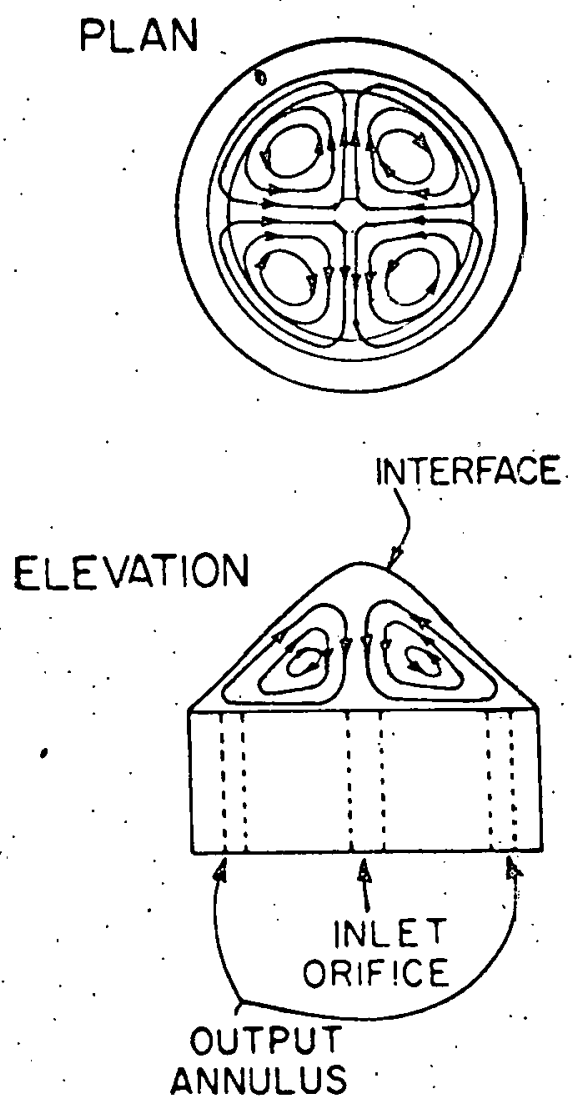

Figure $2 b$
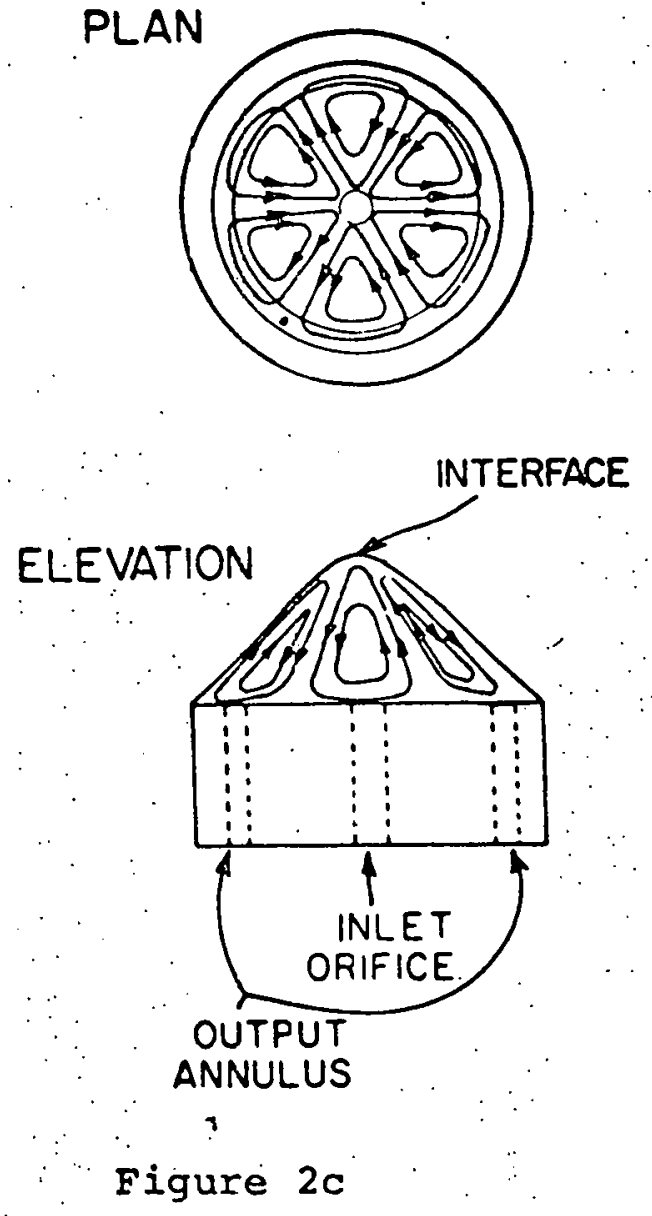

م 
triangular in shape, as shown in Figures $2 b$ and $2 c$. These results are summarized in Table 2 .

From Figure 2 and Table 2 it is clear that only an even number of patterns were observed. It was not possible to obtain three or five patterns because under these conditions, illustrated in Figure 3, the particles would have had to move in the opposite directions at the same point in region $A$ of the interface.

The regions of two, four and six patterns are shown in Figure 4. Each of the curves in Figure 4 is for a constant Reynolds number obtained by the relation:

$$
N_{R e}=\frac{\rho D_{N}(v)}{\mu}=\alpha v
$$

where

$$
\begin{aligned}
& \rho=\text { density of drop fluid gm./cc. } \\
& D_{N}=\text { orifice diameter } \mathrm{cm} . \\
& v=\text { velocity through orifice } \mathrm{cm} \cdot / \mathrm{sec} \\
& \mu=\text { viscosity of drop fluid } \mathrm{gm} . / \mathrm{cm} \cdot / \mathrm{sec} \\
& \alpha=\frac{\rho D_{N}}{\mu} \text { sec. } / \mathrm{cm} .
\end{aligned}
$$

Two patterns were observed on the interface of the drop at each of the experimental points lying between constant Reynolds number curves of 8 and 34 (region B in Figure 4). Similarly four and six patterns were observed at each of the experimental points between Reynolds number curves of 60 
Table 2. Number of patterns on the interface of the drop as a function of range of Reynolds number

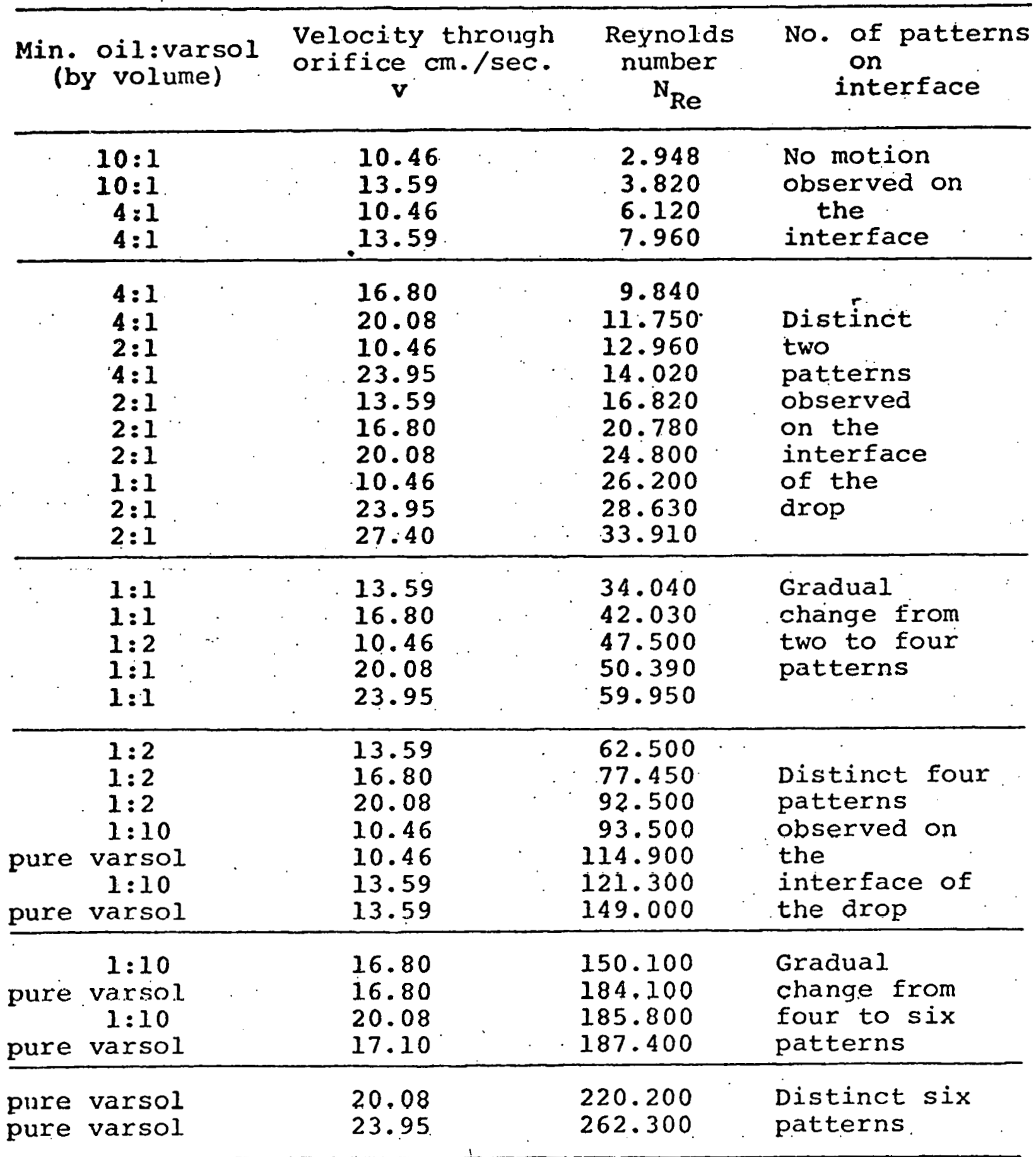

Further increase in Reynolds number led to unstable drop 


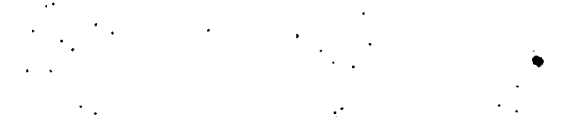

Figure 3. Diagram of hypothetical three pattern flow not observed experimentally. The particles would have to move in opposite directions in region A 


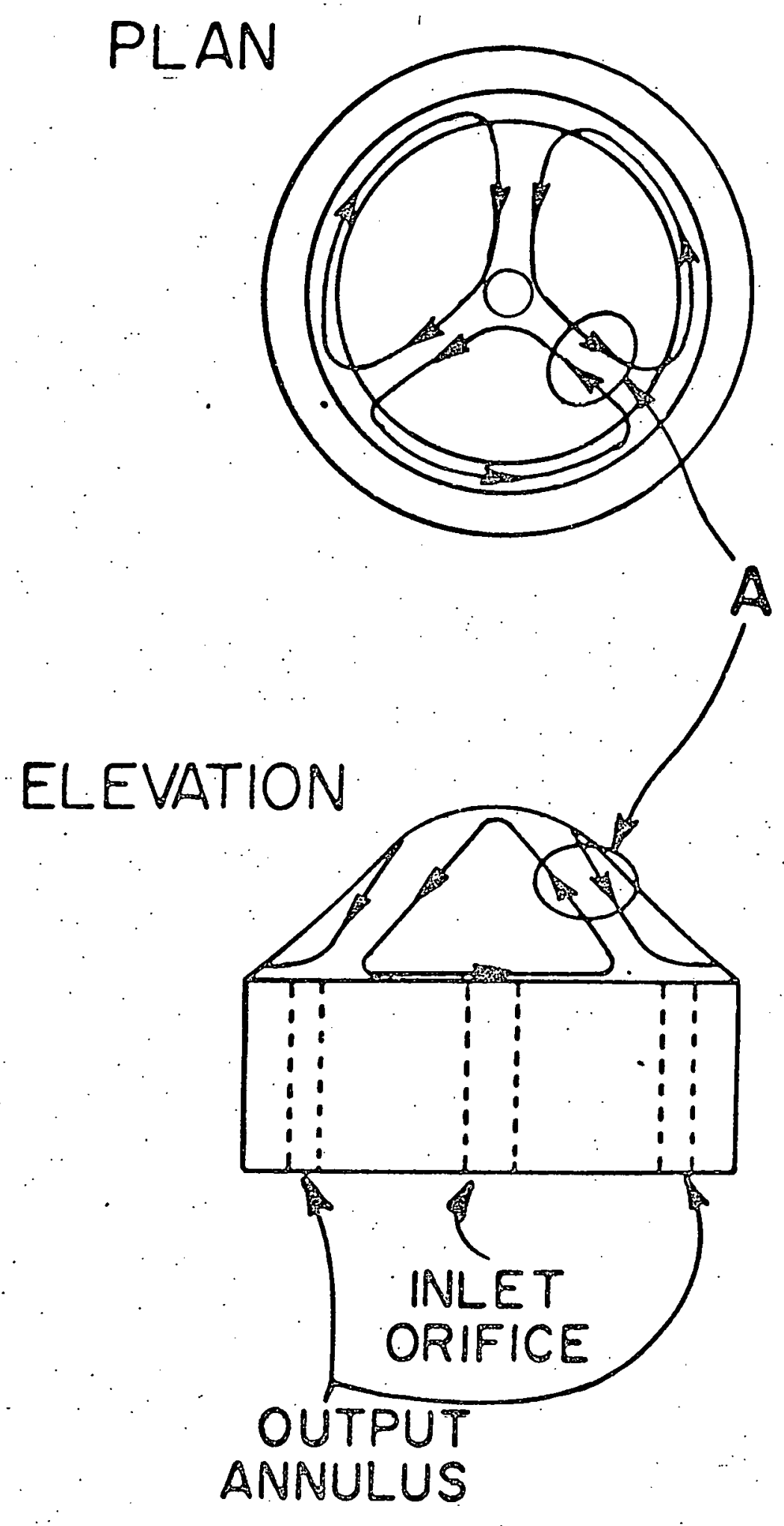


Figure 4, $\alpha$ vs. $v$ curves showing regions of 2,4 , and 6 pattern flows

Region $\mathrm{A}-$ No motion on the interface of the drop

B. - 2 patterns on the interface of the drop

C - Gradual change from two to four patterns

D - 4 patterns on the interface of the drop

E - Gradual change from four to six patterns

F - 6 patterns on the interface of the arop G - The drop becomes unstable above region

Thick lines correspond to 0 to 1008 circulation within the bulk of the drop. The left end of the lines correspond to 0 o circulation while the right end of the lines correspond to $100 \%$ circulation 


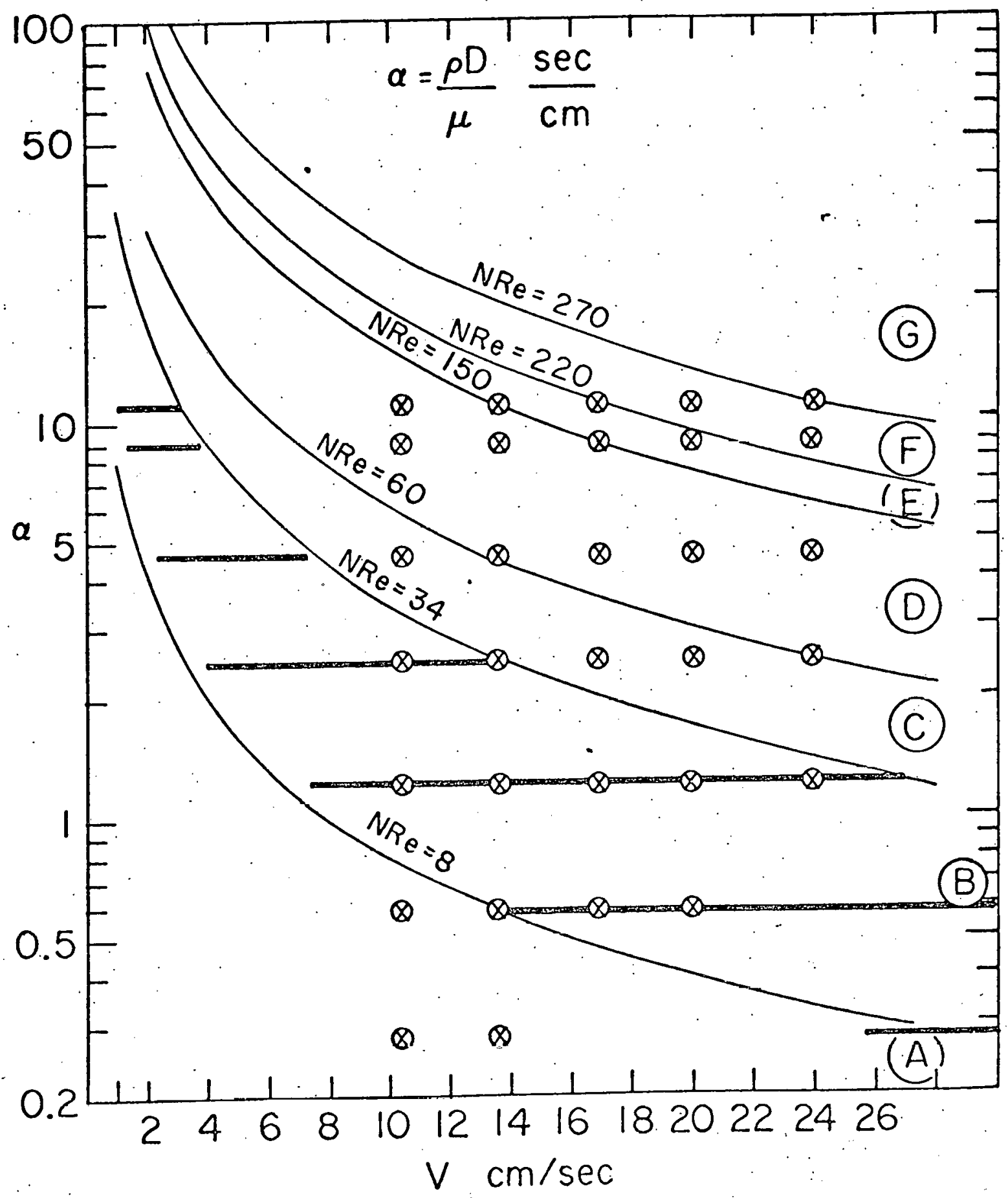


and 150 (region $D$ in Figuce 4) and 220 and 270 (region $F$ in Figure 4) respectively.

Weathers (1970) studied internal circulation within the bulk of the drop in region $B$ and concluded that the internal circulation within the bulk of the drop changed from 0 to $1008^{1}$ as Reynolds number changed from 8 to 34 . This has been shown in Figure 4 by heavy horizontal lines which represent the range of velocities for a given mixture of constant $\alpha$, over which the circulation within the bulk of the drop changed from $0 \%$ (corresponding to the left end of the line) to $100 \%$ (corresponding to the right end of the line). The values corresponding to $0 \%$ circulation and $100 \%$ circulation were obtained by using his empirical correlations: $v$ = $1.18 \mu^{0.83}$ and $v=3.14 \mu^{0.97}$ respectively.

There exists a distinct relation between the motion of the particles on the interface of the drop and the internal circulation within the bulk of the drop. Both internal. circulation and interfacial motion were absent in region $A$ of Figure 4 where $\mathrm{N}_{\mathrm{Re}}<8$. This implies that shearinduced interfacial motion occurs only in the presence of internal circulation within the bulk. Further, only two patterns were observed on the interface when the circulation within the bulk of the drop changed from 0 to $100 \%$. Surface

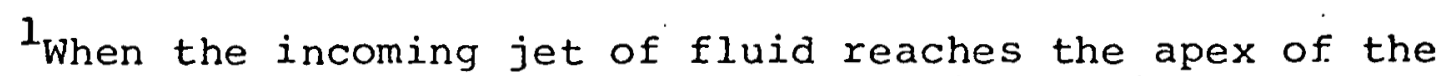
drop, the extent of internal circulation is considered to be $100 \%$. 
motion with more than two patterns occurred oniy after complete internal circulation within the drop had been achieved.

Even though there existed a relation between the motion of the particles on the interface of the drop and internal circulation within the bulk, the nature of the motion of the particles on and underneath the surface was different. For the entire range of Reynolds number from 8 to 270 , the particles within the bulk of the drop always moved fadially away from the inlet orifice in a straight line. On the other hand, on the interface of the drop, the particles moved in elliptical or triangular patterns. The reason for such a behavior may be due to the fact that at steady state and in the absence of mass transfer, the mass on the interface of the drop should be conserved. The movement of the particles in the radial direction away from the center of the nozzle creates depletion of mass in a small circular region around the apex of the drop. In order to satisfy a material balance in this small circular region of the interface around the apex of the drop, there must be particles travelling radially towards the apex at the same mass rate at which they

leave. This condition of mass balance on the interface of drop is clearly satisfied by the motion of particles in the form of elliptical and triangular patterns. The speed of the particles on the interface was measured as they moved along path $A B C D E F G H I$ as shown in Figure 5 , which 


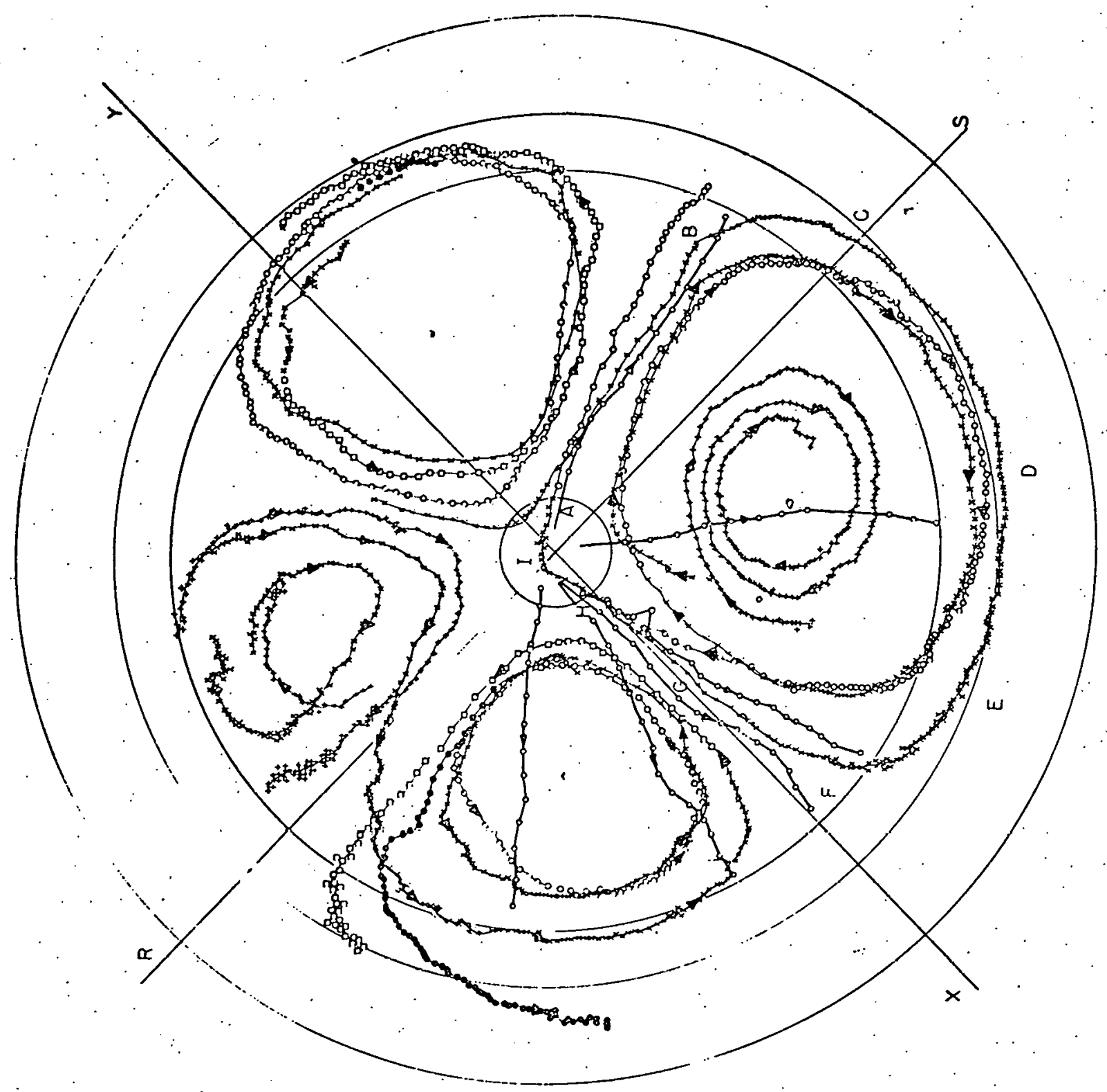

Figure 5. The actual particle paths on the interface of a drop of fluid having viscosity of $2.37 \mathrm{cp}$. and for which Reynolds number based on the inlet orifice diameter was 77.45 
shows actual particle paths on the interface traced from a film of a drop of fluid having a viscosity of $2.37 \mathrm{cp}$. and for which the Reynolds number based on the inlet orifice diameter was 77.45. Each of two consecutive points on Figure 5 corresponds to a time interval of $1 / 32$ second. The calculations were made by using the relationship Speed $=$

Distance between two consecutive points as measured from Figure 5 time interval $x$ magnification.

To account for the $z$ component of the motion, the above speed was divided by the cosine of the angle $\theta$ made by the tangent to the interface. It was not possible to obtain the values of $\theta$ from the films because these films were taken by placing the camera vertically above the drop. Therefore the angle $\theta$ was estimated from a drawing of the approximate shape of the drop. The particle reached a maximum speed of $1.1 \mathrm{~cm} . / \mathrm{sec}$. on the interface between points $A$ and $B$ as shown in Figure 6 . - Similar calculations made from a film of a drop of pure varsol as the drop phase with a Reynolds number of 220 (viscosity $=0.96 \mathrm{cp}$.$) gave a plot of the same shape as that in Figure 6,$ but with a maximum speed of the order of $4 \mathrm{~cm} . / \mathrm{sec}$. between points $A$ and $B$. 
The speed of the particles just underneath the interface was also measured. The heavy radial lines extending from inlet orifice to the outer output annulus in Figure 5 show actual particle paths underneath the interface. The speed of these particles was obtained by using relationship 1 and a maximum speed of the order of $1.8 \mathrm{~cm} . / \mathrm{sec}$. was obtained at the same point (between points $A$ and $B$ ) where the interfacial velocity was maximum.

Even though it is fairly simple to obtain the average inlet velocity of the incoming jet of fluid, it is difficult to measure experimentally how the speed of the jet varies as it moves towards the apex of the drop. After leaving the inlet. nozzle, the liquid jet undergoes both lateral diffusion and deceleration due to turbulence generated at the verges of the jet, simultaneously incorporating and accelerating liquid from the surrounding region into the main stream. M. L. Albertson (1950) in his study of the diffusion of submerged jets obtained the following relationship relating the changes in speed of liquid issuing from a jet to the nozzle diameter and to the distance $Y$.from the nozzle as,

$$
\mathrm{U}_{\mathrm{Z} / \mathrm{U}_{\mathrm{L}}}=1+0.083\left(\mathrm{Y} / \mathrm{D}_{\mathrm{N}}\right)+0.0128\left(\mathrm{Y} / \mathrm{D}_{\mathrm{NV}}\right)^{2} \mathrm{Y} / \mathrm{D}_{\mathrm{N}}<6.2
$$




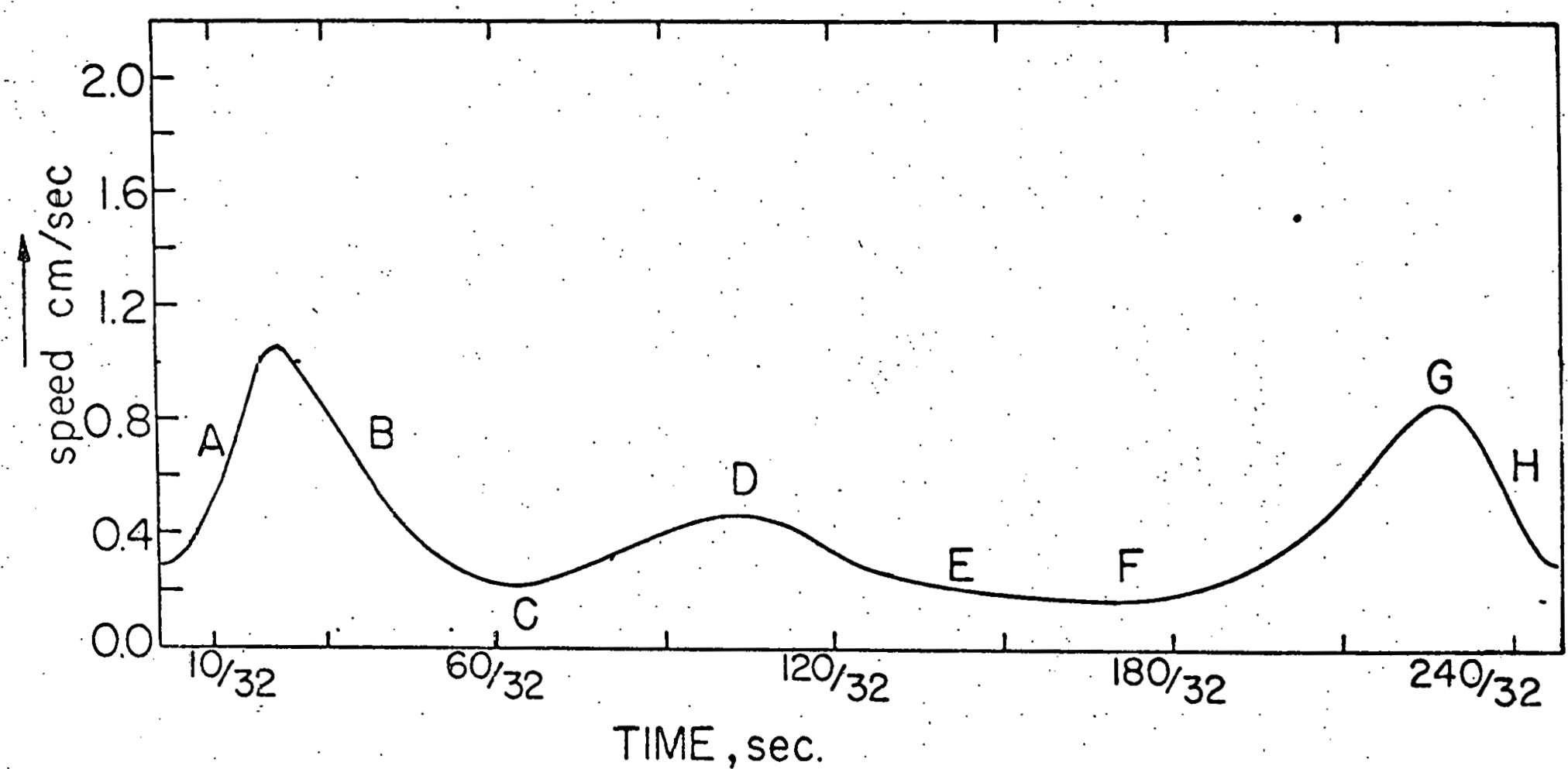

Figure 6. The speed of a particle on the interface as it moves along path ABCDEFGHI as shown in Figure 5 
where

$$
\begin{aligned}
\mathbf{u}_{\mathrm{L}}= & \text { average linear velocity of liquid out of nozzle, } \\
& \text { cm./sec. } \\
\mathbf{U}_{\mathbf{Z}}= & \text { corrected linear velocity, cm./sec. } \\
\mathbf{Y}= & \text { height above the tip of inlet nozzle, cm. }
\end{aligned}
$$

At a height of $0.8 \mathrm{~cm}$. from the nozzle $(Y=0.8)$, the ratio of $U_{Z} / U_{I}$ was found to be 1.973 as obtained by using the above relationship. Thus

$$
\mathrm{U}_{\mathrm{Z}} / \mathrm{U}_{\mathrm{L}}=1.973 \text {, when } \mathrm{Y}=0.8 \mathrm{~cm} \text {. }
$$

The height of the apex of the drop from the nozzle in all the experiments was maintained at $1 \mathrm{~cm}$. This was done by closing slightly the liquid withdrawal valve thus letting more liquid go into the drop than the amount being withdrawn. Once the drop grew to the correct size, the liquid withdrawal valve was opened fully, thus maintaining the constant volume of the drop. Using $Y / D_{N}<6.2$ (relationship 2), for $D_{N}=0.132 \mathrm{~cm}$, it could be shown that $Y$ should be less than 0.8184 . Therefore $\mathrm{Y}=0.8$ was selected in the above calculations. The ratio of $U_{Z} / U_{L}=1.973$. for $\mathrm{Y}=0.8 \mathrm{implied}$ that the speed near the apex of the drop was 1.973 times the average inlet speed.

The speed measurements and calculations in the various regions of the drop as obtained in the two previous paragraphs have been summarized in Table 4 for Reynolds numbers of 77.45 and 220.00 . Table 4 also shows the average speed at 
Table 4. The speed values in different regions of the drop

\begin{tabular}{|c|c|c|c|c|c|}
\hline $\mathrm{N}_{\mathrm{Re}}$ & $\begin{array}{c}\text { Average } \\
\text { speed of } \\
\text { withdrawal } \\
\text { (cm./sec.) }\end{array}$ & $\begin{array}{l}\text { Maximum } \\
\text { interfacial } \\
\text { speed } \\
\text { (cm./sec.) }\end{array}$ & $\begin{array}{c}\text { Maximum } \\
\text { speed } \\
\text { underneath } \\
\text { the interface } \\
(\mathrm{cm} . / \mathrm{sec} .)\end{array}$ & $\begin{array}{l}\text { Speed } \\
\text { near } \\
\text { apex of } \\
\text { the drop } \\
\text { (cm./sec.) }\end{array}$ & $\begin{array}{c}\text { Average } \\
\text { inlet } \\
\text { speed } \\
\text { (cm./sec.) }\end{array}$ \\
\hline 77.45 & 1.03 & 1.10 & 1.80 & 33.15 & 16.80 \\
\hline 220.00 & 1.23 & 4.00 & - & 39.60 & 20.08 \\
\hline
\end{tabular}

which the liquid was withdrawn from the annulus, as obtained by dividing the volumetric flow rate by the area of the annulus.

As explained in the previous paragraph, the two; four and six pattern flows on the interface were symmetrical in nature. From Figure 5, it is clear that path FGH shows particles on the interface moving towards the center while particles only a short distance below the interface are moving away from the center in the opposite direction (shown by. heavy lines). If a cross-section of the drop is taken along $X Y$, the particle paths would appear as shown in Figure $7 \mathrm{a}$. similarly Figure $7 \mathrm{~b}$ shows a cross-section of the drop along RS in Figure 5, in which particles on the interface as well as those within the bulk phase moved in the same direction. The speed of the particles on the interface and within the bulk of the drop along path FGH and $A B$ are plotted in Figures 8 and 9 respectively. In these figures motion away from the 

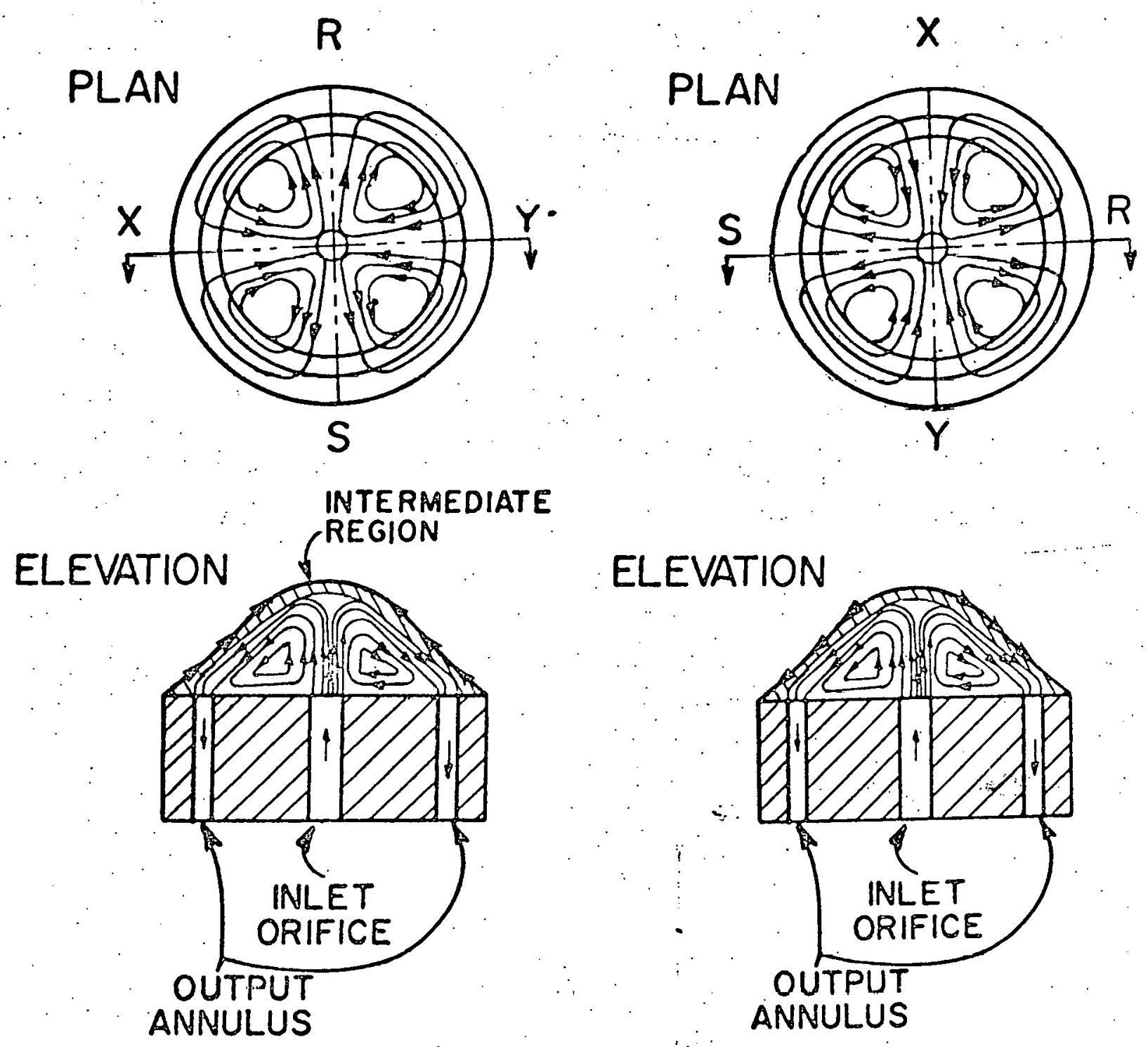

ELEVATION

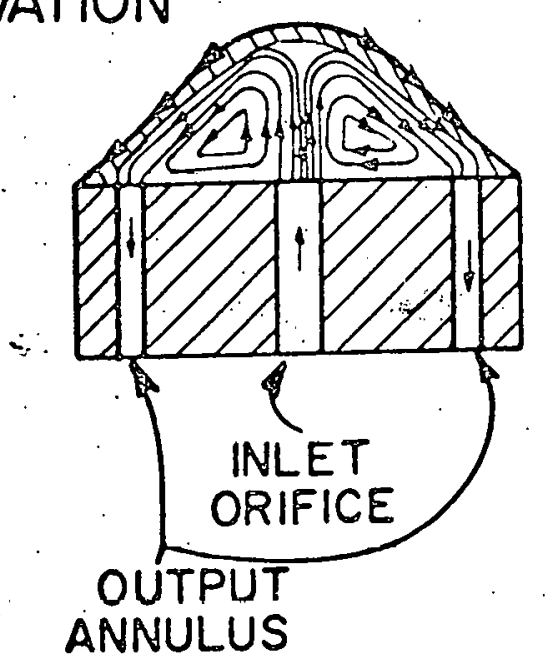

Figure 7a. Particle paths on and underneath the interface when crosssection is taken along Figure 7b: Particle paths on and underneath the interface when crosssection is taken along RS of Figure 5 


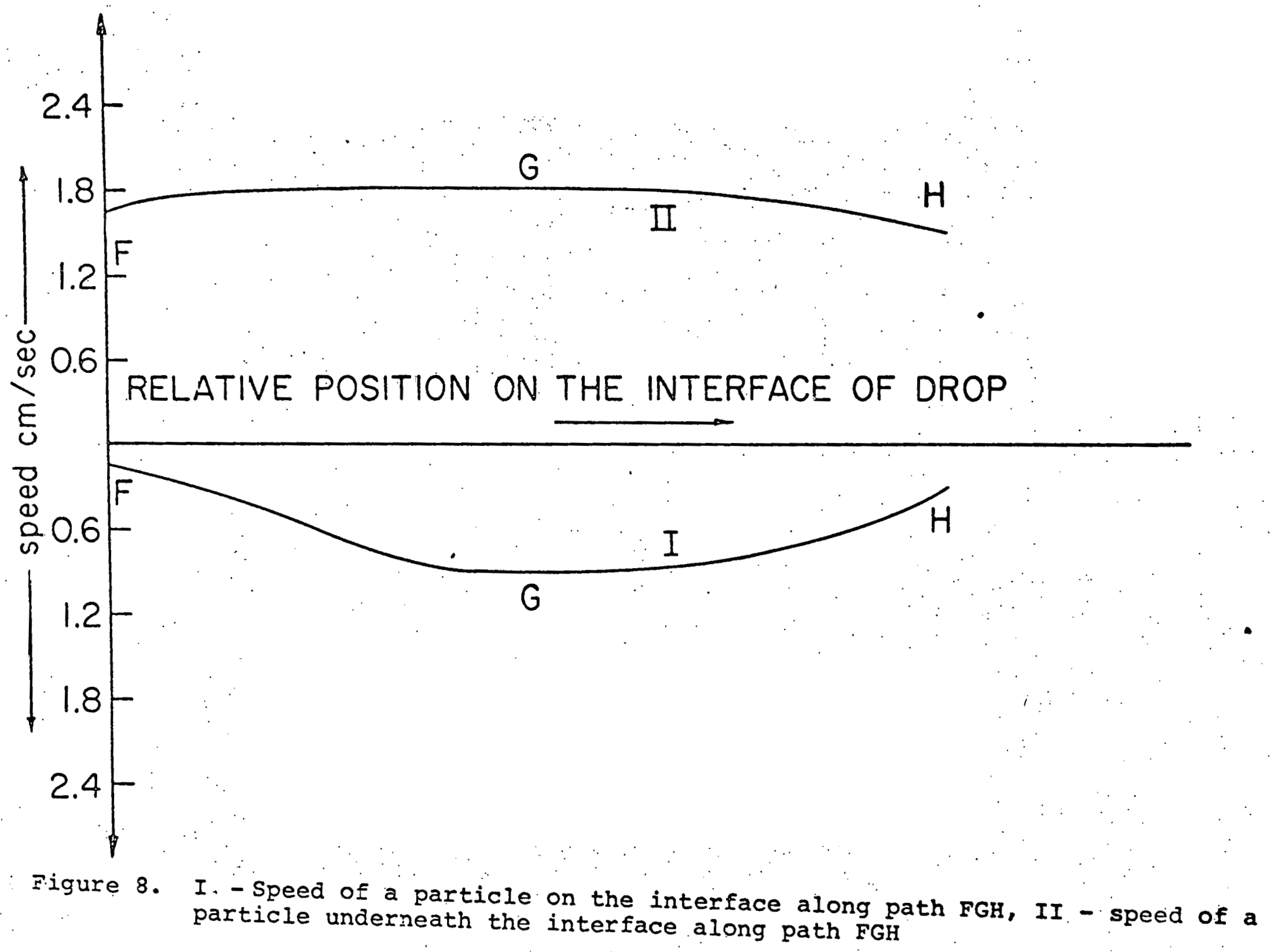




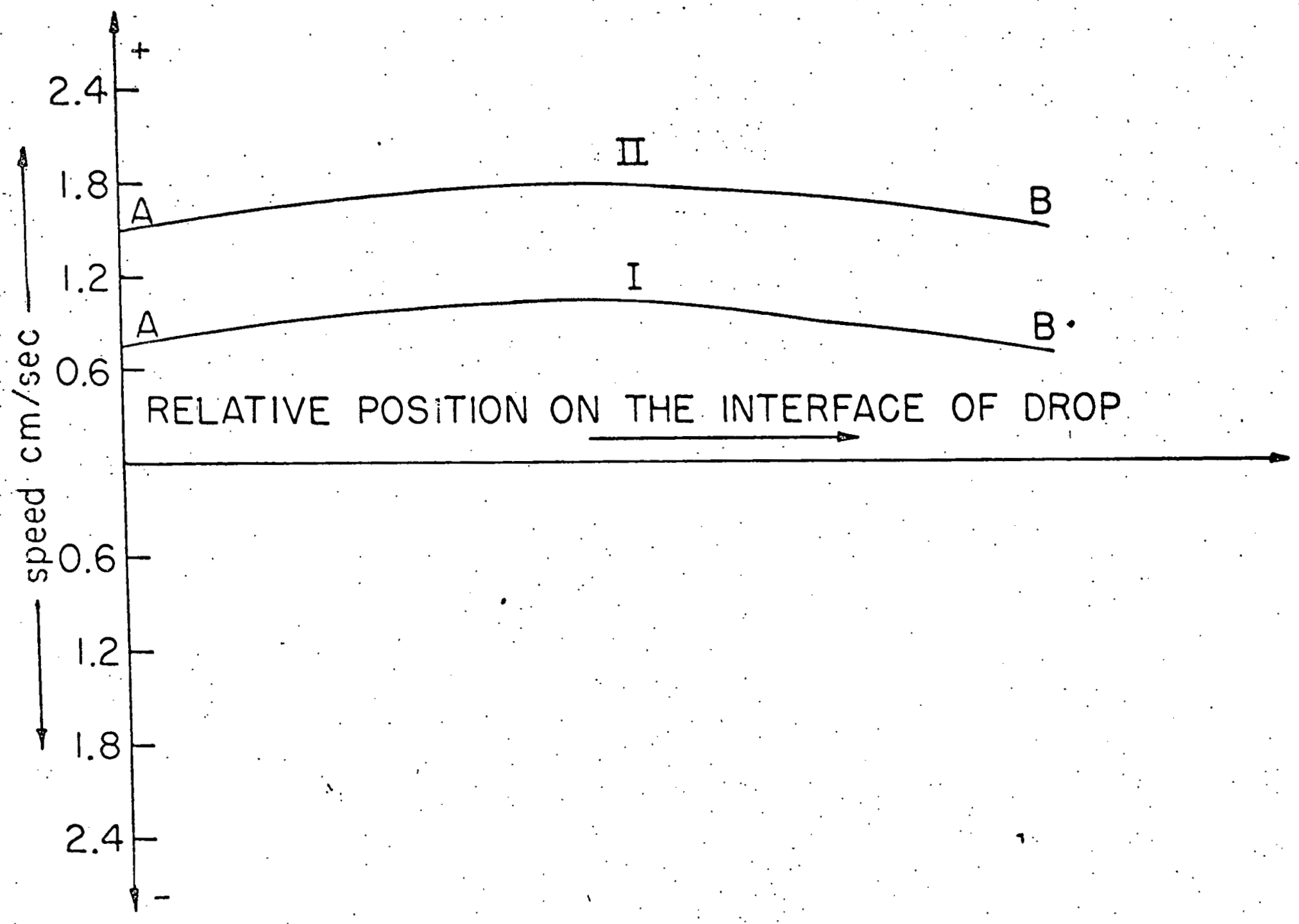

Figure 9. I - speed of a particie on the interface along AB, II - speed of a particle underneath the interface along path $A B$ 
apex of the drop is considered positive and motion towards the apex is negative. The differrence between the values of the speed on and underneath the interface is shown in Figure 10."The difference in speed along FGH showed a maximum at point $G$ indicating that the shear rate was a maximum there. However, shear rate along $A B$ appeared to be constant as shown by horizontal line in Figure 10 .

The nature of the gradual change from two to four patterns and from four to six patterns was not clear. However, from the observations made in Reynolds number range of 150220, the mode of change from four to six patterns was postulated and is explained in Figure 11. When the Reynolds number crossed 150, the two of the four patterns split into halves (Figure $11 \mathrm{~b}$ ), thereby giving four patterns $\mathrm{A}_{1}, \mathrm{~A}_{2}$, $C_{1}$ and $C_{2}$ which are smaller in size than patterns $B$ and $D$. As the Reynolds number was increased, the patterns $\mathrm{A}_{1}, \mathrm{~A}_{2}$, $C_{1}$ and $C_{2}$ expanded in size and patterns $B$ and $D$ became smaller (Figure 1lc) until at a Reynolds number of 220 all four patterns were of equal size.

Since the drop experiments were carried out in the absence of mass transfer and surface active agents, motion on the interface should result due to shear transmitted to the interface by internal motion of the fluid. The speed measurements of this shear induced motion as shown in Figure 6 shows that particles did not move with uniform. speed on 


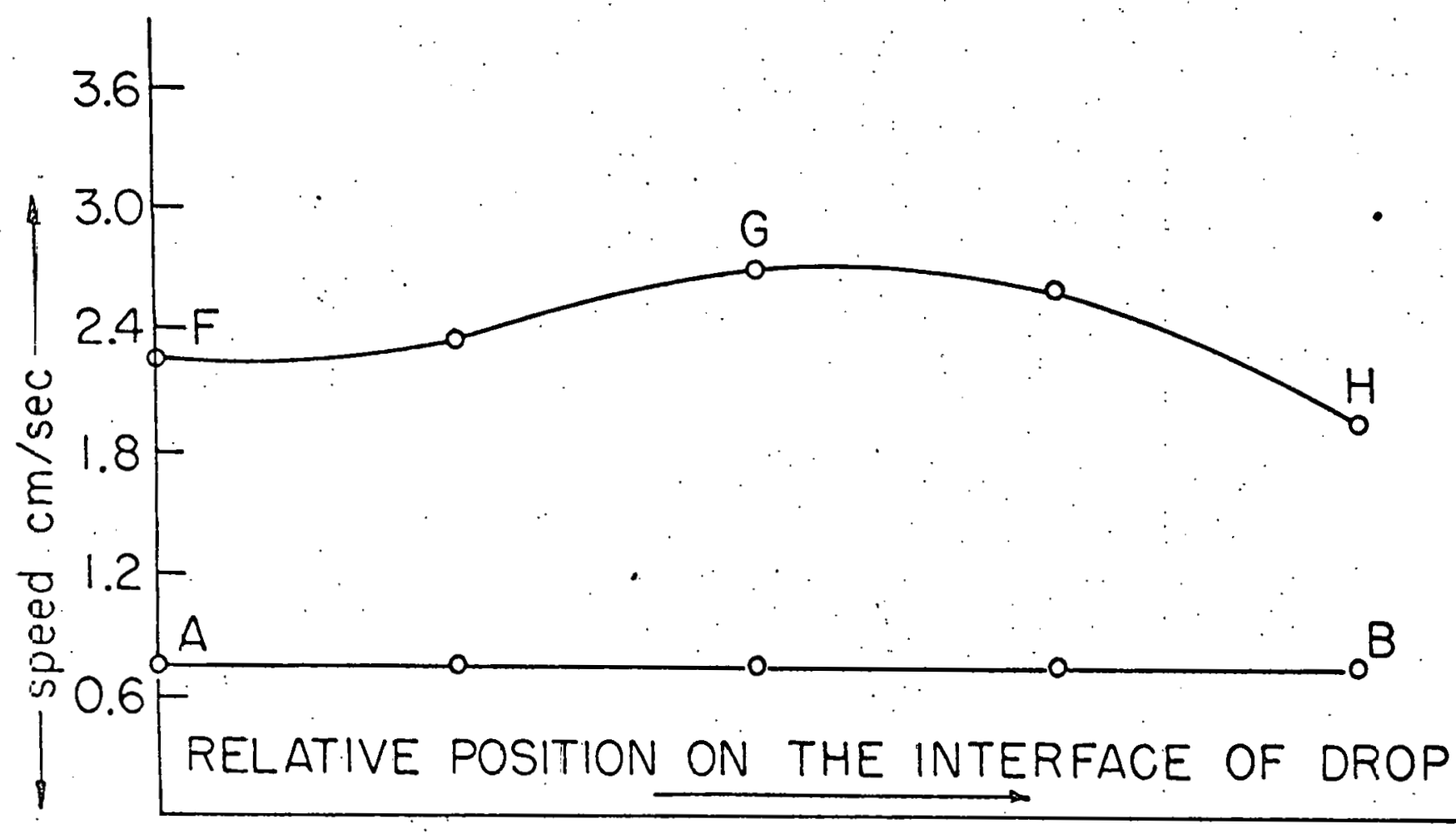

Figure 10. The difference between the absolute speed values of particles on and underneath the interface of the drop along paths $F G H$ and $A B$ 
Figure 11. Postulation of mechanism of gradual change from 4 to 6 patterns over a Reynolds number range of $160<\mathrm{N}_{\mathrm{Re}}<220$

a. Four symmetrical patterns on the interface for $\mathrm{N}_{\mathrm{Re}}<160$

b. Each of patterns $A$ and $C$ split into two patterns when $\mathrm{N}_{\mathrm{Re}}$ increases above $160,{ }^{A}$ ' $A_{2}, C_{1}$, and $C_{2}$ are smaller in size than $B$, and $D$

c. As Reynolds number is increased to a range of 160-220, patterns $A_{1}, A_{2}, C_{1}$, and $C_{2}$ expand in size and $B$ and $D$ contract in size

d. For Reynolds numbers above 220 , all six patterns become of equal size 


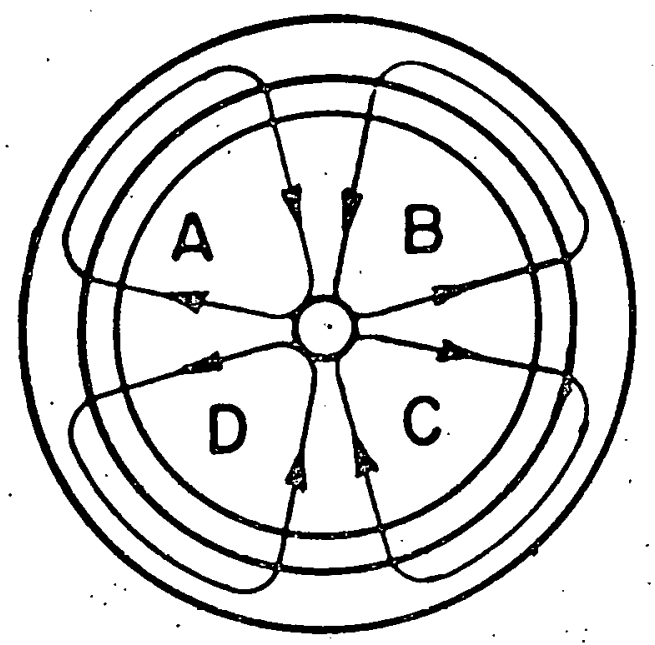

Figure lla

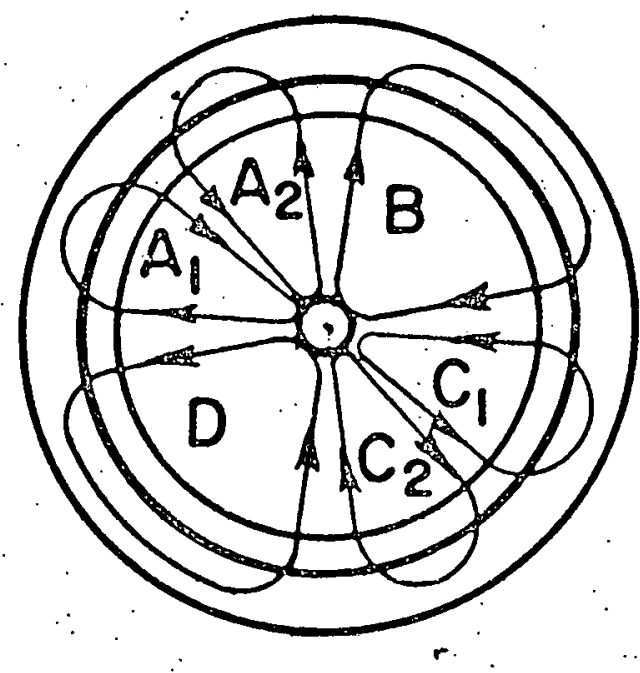

Figure $11 b$

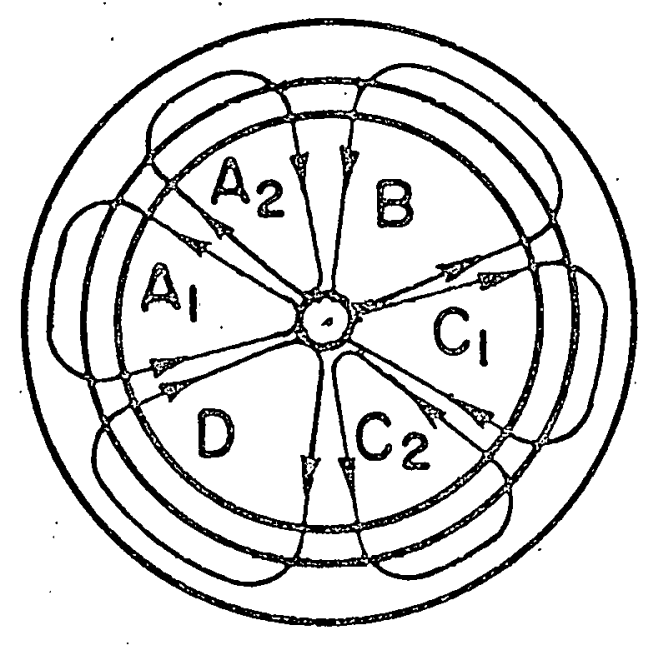

Figure 1lc

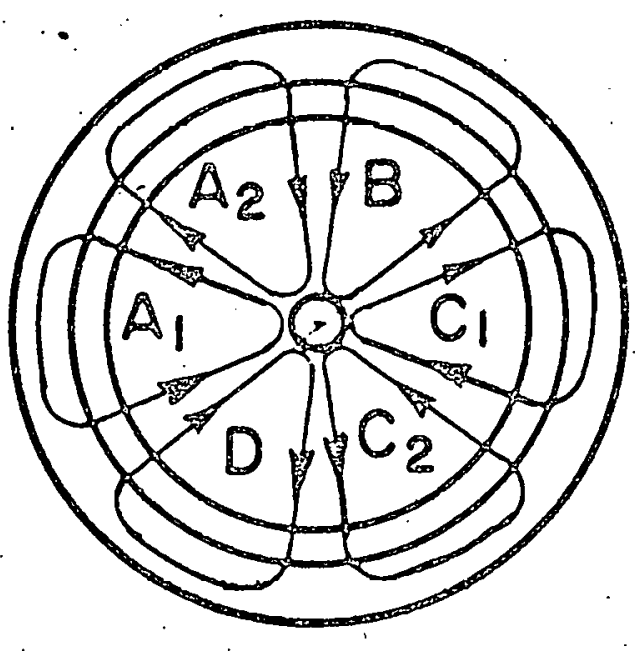

Figure lld 
the interface, but there were regions where particles accelerated and decelerated. The pressure differences on various parts of the interface provided driving force for movement of particles at nonuniform speeds. The net balance of forces arising in the interface due to pressure differences should be zero because there was no net motion of interface of the drop.

\section{Experiment II}

The problem studied in the Experiment $I$ is mainly that of a submerged liquid jet impinging on a curved interface of \{ the drop. It was thought that the study of a submerged water jet impinging on a flat air-water interface could be useful if the height of the air-water interface above the nozzle was kept nearly the same as height of the apex of the drop from the nozzle which was surrounded by circular boundary. The modifications in the previous experiment and the results of such an experiment are described in the following sections.

\section{Experimental}

In this experiment, the nozzle was surrounded by a glass cylinder of $6.32 \mathrm{~cm}$. diameter, thus forming a circular boundary around the nozzle. A jet of distilled water was forced out of the central orifice by one of the syringes, while the other syringe withdrew distilled water from the bottom 
of the outer chamber (Figure 12). The rate of injection and withdrawal were kept equal, so that the height of the interface above the nozzle remained constant. The jet of water impinged upon the water-air interface, and the motion of hollow glass beads placed on the interface was recorded photographically on Polaroid black and white $4 \times 5$ positive/ negative/type 55 film.

Results and discussion

Figure 13 and 14 show 4 and 6 patterns on the interface corresponding to Reynolds numbers of 410 and 288 respectively. Tables 5 and 6 gives the range of Reynolds numbers over which 4 patterns were seen on the interface. Table 5 shows that for a nozzle diameter of $0.264 \mathrm{~cm} ., 4$ patterns were observed over the Reynolds number range of 69 to 288, but near $\mathrm{N}_{\mathrm{Re}}=288.09$ and when the surface was $1 / 2^{\prime \prime}$ and $1^{\prime \prime}$ above the orifice, the number of patterns oscillated very rapidly between 4 and 6 . This particular result should be considered as unusual because when orifice diameter was $0.132 \mathrm{~cm}$., only 4 patterns were observed for Reynolds number as high as 574 as shown in Table 6 .

In the case of Experiment $I$, the 2-4-6. flow patterns were obtained over a Reynolds number range of 8 to 270 . However, when the jet of water impinged on a flat air-water 


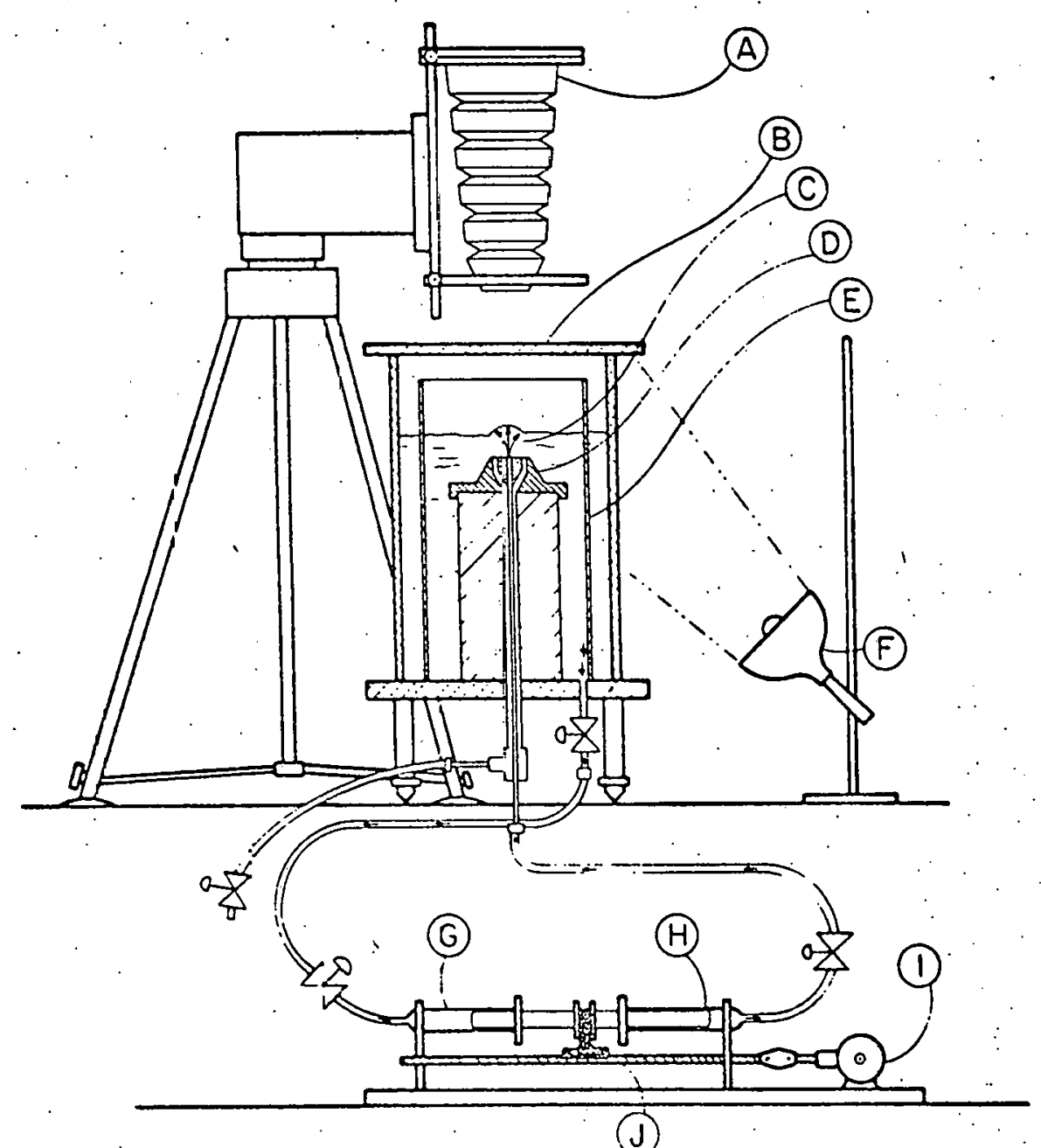

A POLAROID CALUMET CAMERA $4 \times 5$

B OUTER GLASS CHAMBER IFLLED WITH DISTILLED WATER)

C WATER JET STRIKING THE WATER-AIR INTERFACE

D TEFLON. NOZZLE

E INNER GLASS CHAMBER

$F$ PHOTO FLOOD.LAMP

$G$ SYRINGE (WATER IS WITHDRAWN FROM THE BOT TOM OF OUTER GLASS CHAMBER)

H SYRINGE (WATER JET IS FORCEO AGAINST THE WATER-AIR INTERFACE)

I BODINE VARIABLE SPEED MOTOR

J WORM GEAR DRIVE

Figure 12. Schematic diagram of the equipment modified to permit observation of surface flow patterns on a plane air-water interface 


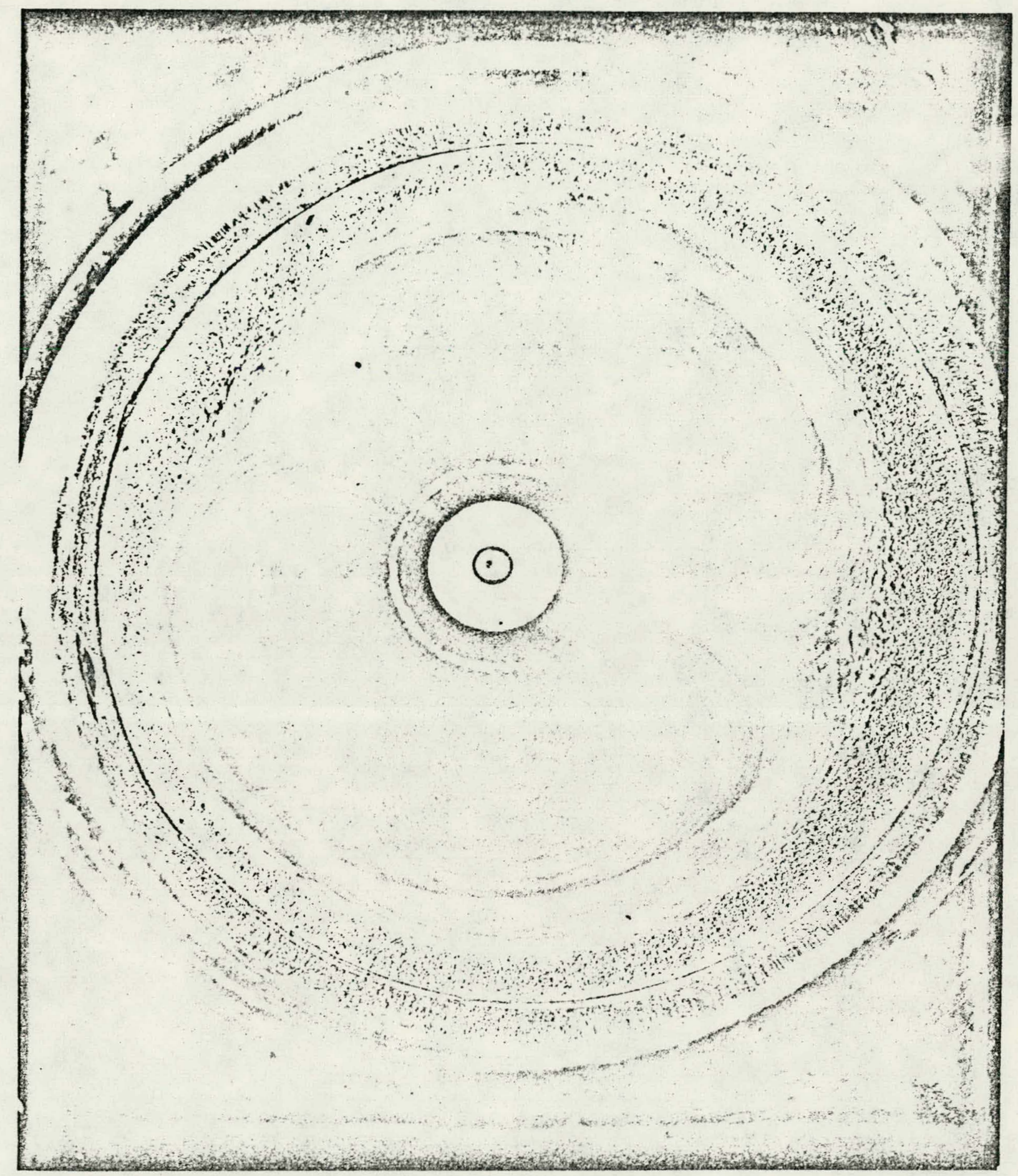

Figure 13. Four patterns on air-water interface corresponding to a submerged water jet of $\mathrm{N}_{\mathrm{Re}}=410.11$ 


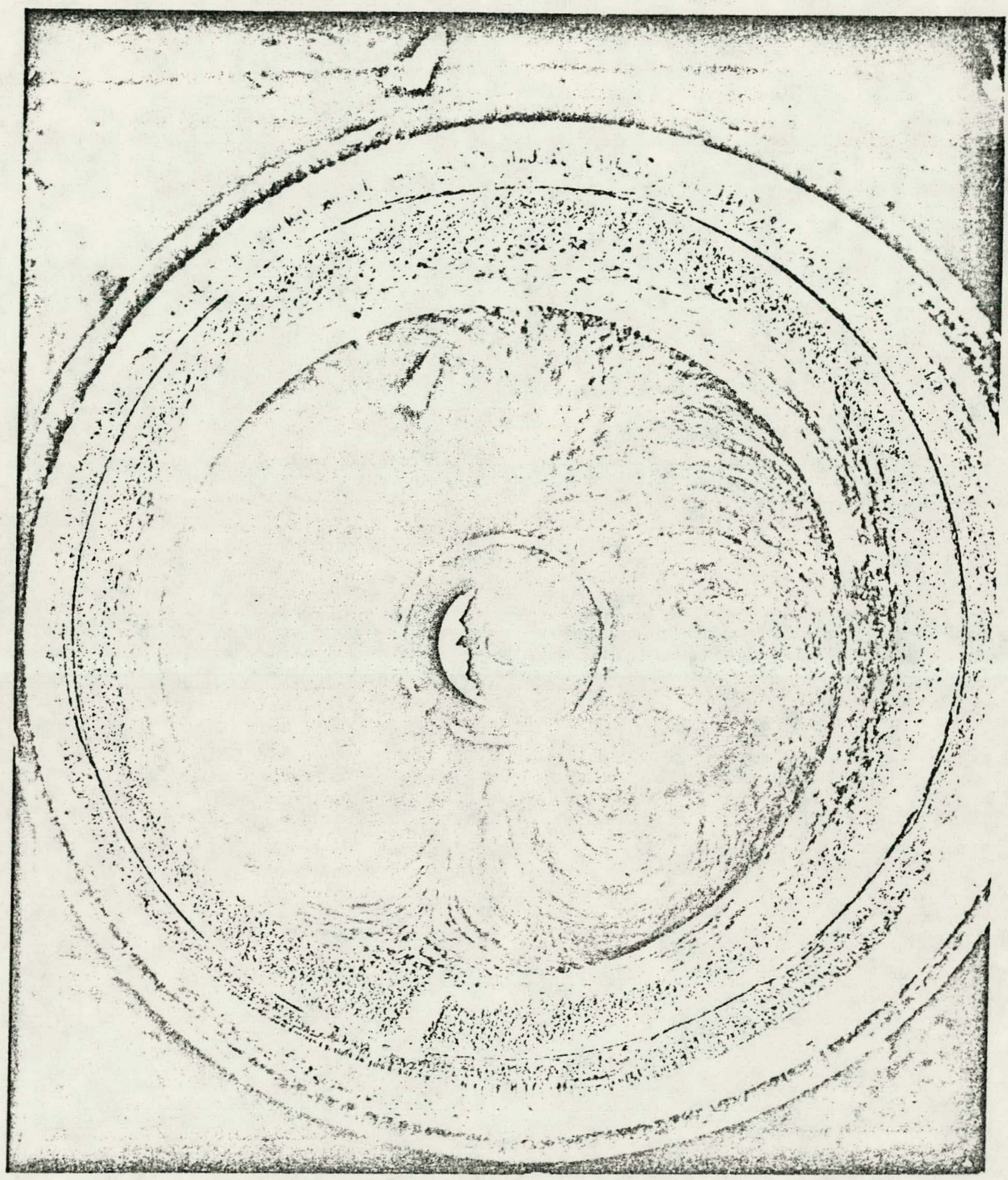

Figure 14. Six patterns on air-water interface corresponding to a submerged water jet of $\mathrm{N}_{\mathrm{Re}}=288.09$ 
Table 5. Number of patterns on water-air interface for different nozzle velocities (nozzle diameter $=0.264$ cm., diameter of glass cylinder surrounding the nozzle $=6.3 \mathrm{~cm} \cdot$ )

\begin{tabular}{|c|c|c|c|c|c|c|}
\hline \multirow{2}{*}{$\begin{array}{l}\text { Velocity } \\
\text { through } \\
\text { nozzle, } \\
\text { 'v' } \\
\mathrm{cm} \cdot / \mathrm{sec} \text {. }\end{array}$} & \multirow{2}{*}{\multicolumn{2}{|c|}{$\begin{array}{c}\text { Npe based on } \\
\text { nozzle dia., } \\
v \text { \& properties } \\
\text { of } \\
\text { water }\end{array}$}} & \multicolumn{4}{|c|}{ Number of patterns for } \\
\hline & & & $\mathrm{h}^{\mathrm{a}}=1 / 2$ & $h^{2}=1$ & $h^{a}=2$ & $h^{a}=2.5$ \\
\hline 2.63 & & $69.4 ?$ & 4 & 4 & 4 & 4 \\
\hline 3.42 & & 90.34 & 4 & 4 & 4 & $r^{4}$ \\
\hline 4.25 & & 112.27 & 4 & 4 & 4 & 4. \\
\hline 5.22 & & 137.09 & 4 & 4 & 4 & 4 \\
\hline 6.03 & & 159,29 & 4 & 4 & 4 & 4 \\
\hline 6.89 & & 182.01 & 4 & 4 & 4 & 4 \\
\hline 7.81 & & 206.30 & 4 & 4 & 4 & 4 \\
\hline 8.64 & & 228.23 & 4 & 4. & 4 & 4 \\
\hline 9.54 & & 252,01 & 4 & 4 & 4 & 4 \\
\hline 10.94 & & 288.09 & $-b$ & $-b$ & 4 & 4 \\
\hline
\end{tabular}

$a_{h}=$ height of water-air interface above the nozzle.

$\mathrm{b}_{\text {Number }}$ of patterns oscillates between 4 and 6 very rapidly, see Figure 14 . 
Table 6. Number of patterns on water-air.interface for different nozzle velocities (nozzle diameter = $0.132 \mathrm{~cm}$., diameter of glass cylinder surrounding the nozzle $=6.3 \mathrm{~cm}$.)

\begin{tabular}{|c|c|c|c|c|c|c|c|}
\hline $\begin{array}{l}\text { Velocity } \\
\text { through }\end{array}$ & $\begin{array}{l}\text { Npe based } \\
\text { nozzle dia }\end{array}$ & $\begin{array}{l}\text { on } \\
a_{:},\end{array}$ & . Numb & er of $p$ & atterns & for & \\
\hline $\begin{array}{l}\text { nozzle, } \\
\text { !v' } \\
\mathrm{cm} \cdot / \mathrm{sec} .\end{array}$ & $\begin{array}{c}v \& \begin{array}{c}\text { propert } \\
\text { of } \\
\text { water }\end{array} \\
\end{array}$ & ties & $h^{a}=1 / 2$ & $\mathrm{~h}^{\mathrm{a}}=1$ & $h^{a}=2$ & $h^{a}=2.5$ & \\
\hline 10.46 & 138.16 & & 4 & 4 & 4 & 4 & \\
\hline 13.59. & 179.50 & .. & 4 & 4 & 4 & 4 & \\
\hline 16.80 & 221.89 & & 4 & 4 & 4 & 4 & \\
\hline 20.08 & 265.22 & & 4 & 4 & 4 & 4 & $\therefore$ \\
\hline 23.95 & 316.33 & & 4 & 4 & 4 & 4 & \\
\hline 27.40 & 361.90 & $\cdot$ & 4 & 4 & 4 & 4 & $\because$ \\
\hline 31.05 & 410.11 & . & 4 & 4. & 4 & 4 & \\
\hline 34.32 & 453.25 & & 4 & 4 & 4 & 4 & \\
\hline 37.91 & 500.68 & & $-b$ & $--^{b}$ & 4 & 4 & \\
\hline 43.47 & 574.11 & & $-b$ & $-b$ & 4 & 4 & \\
\hline
\end{tabular}

$a_{h}=$ height of water-air interface above the nozzle.

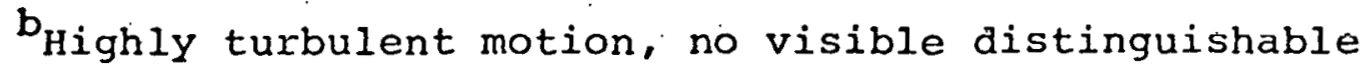
patterns.

interface, only 4 patterns were observed over the entire range from 70 to 540 . The shape of these patterns were triangular and similar to the shape of 4 pattern flows observed on the surface of a drop. It should be noted that the surrounding medium was air in Experiment II, while in 
Experiment I, the surrounding medium was water. Since similar flow patterns were observed in both experiments, the effects of the surrounding phase on the shape of interfacial flow patterns could be assumed negligible. 


\section{CONCLUSIONS AND RECOMMENDATIONS}

i. The particles on the interface of a drop with forced internal circulation followed definite patterns of motion. Two, four, and six flow patterns were observed over a Reynolds number range of 8-270. The shape of these patterns were elliptical for the ţwo pattern flows and triangular for the four and six pattern flows.

2. Similar patterns were observed on an air-water interface when a submerged jet of water impinged against the interface. Four patterns were observed throughout the Reynolds number range of 69 to 574, and the shape of each of the four patterns was approximately triangular.

3. The effect of the surrounding medium on the shape of the interfacial flow patterns was negligible. This was concluded from the fact that similar circulation patterns were observed on the interface in both Experiment $I$ and Experiment II, even though the surrounding medium was water in Experiment $I$ and air in Experiment II.

4. Since the drop experiments were carried out in the absence of mass transfer and surface active agents, the motion on the interface of the drop is the result of shear transmitted to the interface by the internal motion of the fluid. 
5. The drop interface as a whole was in equilibrium, but due to pressure differences, the local forces acted in individual parts of the interface to produce definite regular motion of particles at nonuniform speeds in the interface.

6. The interfacial motion on the interface of arop should be studied in the presence of mass transfer towards and away from the arop and in the presence of interfacial turbulence to determine the relative importance of both shear-induced motion and motion resulting from local differences in interfacial tension. 
IITERATURE CITED .

Albertson, M. L., Y. B. Dai, R. A. Jense, and H. Rouse. 1950. Diffusion of submerged jets. American Society of Civil Engineers Transactions 115: 639-664.

Brodkey, R. S. 1967. The phenomena of fluid motions. Addison-Wesley Publishing Co., Reading, Massachusetts. $737 \mathrm{pp}$.

Burkhart, L. G., P.W. Weathers, and P. C. Sharer. 1976. Internal circulation and mass transfers in forming liquid drops. (Unpublished Manuscript) Energy and Resources Development Administration, Iowa State University, Ames, Iowa.

Constan,.G. I., and S. Calvert. 1963. Transfer in drops under conditions that promote oscillation and internal circulation. American. Institute of Chemical Engineers Journal 9: 109-115.

Gal-or, B., G. E. Klinzing, and L. L. Tavlarides. 1969. Bubble and drop phenomena. Industrial and Engineering Chemistry $69: 21-34$.

Garner, F. H., and J. J. Lane. 1959. Mass transfer to drops of liquid suspended in a gas stream. part II. Experimental work and results. Institution of Chemical Engineers Transactions 37: 162-172.

Garner, F. H., and A. H. P. Skelland. 1951. Liquid-liquid mixing as affected by the internal circulation within droplets. Institute of Chemical Engineers Transactións 29 : $315-321$.

Horton, J. J., T. R. Fritsch, and R. C. Kintner. 1965. Experimental determination of circulation velocities inside drops. Canadian Journal of Chemical Engineering 43: 143-146. 
Humphrey, J.A. C., R. I. Hummel, and J. W. Smith. 1974. Determination of the position of visualized material elements in growing drops. The Canadian Journal of Chemical Engineering 52: 110-113.

Kintner, R. C. 1963. Drop phenomena affecting liquid extraction. Advances in Chemical Engineering $4: 51-$ 94.

Rintner, R. C:, T. J. Horton, R. E. Gravman, and S. Amberkar. 1961. Photography in bubble and drop research. Canadian Journal of Chemical Engineering 39: 235-240.

Kronig, R., and J. C. Brink. 195l. On the theory of extractions from falling droplets. Applied Scientific Research A2: 142-154.

LeVan, M. D. and J. Newman. 1976. The effect of surfactnat on the interfacial velocity of a bubble or drop (Unpublished Manuscript). Department of Chemical Engineering, University of California; Berkeley.

Murty, A. S., and W. E. Ranz. 1963. Interfacial turbulence at the surface of a drop in a liquid-liquid reaction system. American Institute of Chemical Engineers Journal 9: 109-115.

Panno, A., and S. Calvert. 1965. Mass transfer in drops with forced internal circulation. Pages 776-788 in S. Ostrach, and R. H. Scanlan, eds. Development in Mechanics, Vol. 2, Part I. Pergamon Press, New York, N.Y.

Popovich, A. T. and R. L. Hummel. 1967. A new method for non-disturbing turbulent flow measurements very close to a wall. Chemical Engineering Science 22: 21-25.

Poreh, M., and J. E. Cermak. 1959. Flow characteristics of a circular submerged jet impinging normally on a smooth boundary. 6th Midwestern Conference on Fluid Mechanics $6: 198-213$.

Rajan, S. M., and W. J. Heideger. 1971. Drop formation mass transfer. American Institute of Chemical Engineers Journal 17(1): 202-206.

Resnick, W., and B. Gal-or. 1968. Gas-liquid dispersions. Advances in Chemical Engineering 7: 295-395. 
Rose, P. N. and R. C. Kintner. 1966. Mass transfer f'rom large oscillating drop. American Institute of Chemical Engineers Journal 12: 530-534.

Sandry, T. D. 1973. Drop shapes and internal flow patterns by numerical solution of the Navier-stokes equations. Unpublished Eh:D. thesis. Iowa State University, Ames, Iowa.

Schechter, R. S., and R. W. Farley. 1963. Interfacial tension gradients and droplet behavior. Canadian Journal of Chemical Engineering 41: 103-107.

Sharer, P. C. 1972. Mass transfer from a drop with forced internal circulation. Unpublished M.S. thesis. Iowa State University, Ames, Iowa.

Soo, S. L. 1967. Fluid dynamics of multiphase systems. Blaisdell Publishing Co., Waltham, Massachusetts. 524 pp.

Tavlaride, L. L., C. A. Coulaloglov, M. A. Zeitlin, G. E. Klinzing, and B. Gal-or. 1970. Bubble and drop phenomena: Industrial and Engineering Chemistry 62: 6-27.

Weathers, P. W. 1970. Internal flow patterns of forming drops. Unpublished M.S. thesis. Iowa State University, Ames, Iowa. 


\section{ACKNOWLEDGMENTS}

The author wishes to express his appreciation and thanks to Dr. L. E. Burkhart for his guidance and encouragement throughout this project. Thanks are also due Mr. Harvey Jensen and Mr. James A. Herriott for their assistance with various portions of this investigation. 